\title{
Biologic Therapy in Head and Neck Cancer: A Road with Hurdles
}

\author{
Pol Specenier and Jan B. Vermorken \\ Department of Medical Oncology, Antwerp University Hospital, Wilrijkstraat 10, 2650 Edegem, Belgium \\ Correspondence should be addressed to Jan B. Vermorken, jan.b.vermorken@uza.be
}

Received 11 March 2012; Accepted 11 April 2012

Academic Editors: A. Celetti, K. J. Dornfeld, and F. Kuhnel

Copyright (C) 2012 P. Specenier and J. B. Vermorken. This is an open access article distributed under the Creative Commons Attribution License, which permits unrestricted use, distribution, and reproduction in any medium, provided the original work is properly cited.

\begin{abstract}
The epidermal growth factor receptor (EGFR) is overexpressed in the vast majority of cases of squamous cell carcinoma of the head and neck (SCCHN). A high EGFR expression is associated with an unfavorable prognosis. Cetuximab is a chimeric human/murine IgG1 antibody which binds with high affinity to the EGFR. It is the only targeted agent which got approval for the treatment of SCCHN from the regulatory agencies of Europe and the United States, both in locoregionally advanced disease, in association with radiation, and in recurrent/metastatic disease. The outcome of trials involving other EGFR-directed monoclonal antibodies, that is, zalutumumab and panitumumab, was consistent with the results with cetuximab. However these trials failed to meet their primary endpoint. The results with EGFR-directed tyrosine kinase inhibitors have been disappointing. Other potential targets for treatment in SCCHN include the entire ErbB family, the vascular endothelial growth factor (VEGF) and its receptor (VEGFR), the insulin-like growth factor 1 receptor (IGF-1R), the insulin receptor (IR), histone deacetylases (HDAC), the mammalian target of rapamycin (mTOR), the platelet-derived growth factor receptor (PDGFR), heat-shock protein 90 (HSP90), nuclear factor-kappa $\mathrm{B}(\mathrm{NF}-\kappa \mathrm{B})$, aurora A or B, and phosphatidylinositol 3-kinase (PIK3CA).
\end{abstract}

\section{Introduction}

Worldwide, squamous cell carcinoma of the head and neck ( $\mathrm{SCCHN}$ ) is the sixth most common cancer and is diagnosed in more than 600,000 patients each year [1]. A better understanding of its biology has been accompanied by the introduction of a large and rapidly expanding number of targeted agents into its management strategies [2]. Planned and ongoing trials in SCCHN involving targeted agents are summarized in Tables 1, 2, 3, and 4 [3]. Potential targets include the epidermal growth factor receptor (EGFR) and the ErbB family, the vascular endothelial growth factor (VEGF) and its receptor (VEGFR), Insulin-like Growth Factor 1 Receptor (IGF-1R), insulin receptor (IR), histone deacetylase (HDAC), mammalian target of rapamycin (mTOR), plateletderived growth factor (PDGFR), Heat-shock protein 90 (HSP90), Nuclear factor-kappa B (NF- $\kappa$ B), aurora A or B, phosphatidylinositol 3-kinase (PIK3CA).

\section{EGFR-Directed Therapies}

The Epidermal Growth Factor Receptor (EGFR) belongs to the ErbB family of receptors which includes four members: EGFR/ErbB1, ErbB2/Her2/neu, ErbB3, and ErbB4. EGFR consists of an extracellular $\mathrm{N}$-terminal ligand-binding domain, a hydrophobic transmembrane domain, and a C-terminal intracellular domain, which includes the tyrosine kinase domain and the autophosphorylation sites. The Epidermal Growth Factor Receptor (EGFR) is overexpressed in the vast majority of cases of Squamous Cell Carcinoma of the Head and Neck (SCCHN) [4]. A high EGFR expression and an increased EGFR gene copy number are associated with an unfavorable prognosis [5-7]. Two of the potential EGFR targeting strategies that are currently in use in the treatment of SCCHN are the monoclonal antibodies directed at the extracellular domain of the receptor and the small molecule and ATP-competitive tyrosine kinase inhibitors (TKIs). 
TABLE 1: Planned or ongoing trials with cetuximab in SCCHN.

\begin{tabular}{|c|c|c|c|}
\hline Trial phase & Disease setting & Associated treatment & Comparator \\
\hline \multirow{5}{*}{ Phase III } & LA resectable & TP before surgery & Surgery + RT \\
\hline & LA & RT (after TPF ICT) & $\mathrm{RT}+\mathrm{P}$ \\
\hline & LA & RT after TPF & $\mathrm{RT}+\mathrm{P}$ or CRT \\
\hline & $\mathrm{LA} \mathrm{HPV} \mathrm{+} \mathrm{OPH}$ & $\mathrm{RT}$ & $\mathrm{P}$ \\
\hline & LA resected & $\mathrm{RT}$ & none \\
\hline \multirow{5}{*}{ Randomized phase II } & LA & RT & $\mathrm{P}$ \\
\hline & LA & TPF or paclitaxel + carbo & \\
\hline & LA & Adjuvant after CRT + cetuximab & none \\
\hline & $\mathrm{R} / \mathrm{M}$ & Temsirolimus & \\
\hline & LA ICT & TPF or paclitaxel/P & \\
\hline \multirow{17}{*}{ Single arm phase II } & LA & $\mathrm{RT}+(\mathrm{P}$ or carbo $)+\mathrm{NABP}$ & \\
\hline & LA & (Accelerated) RT & \\
\hline & LA ICT & TPF & \\
\hline & LA ICT & $\mathrm{TP}$ & \\
\hline & LA ICT & Paclitaxel/P $\rightarrow$ RT & \\
\hline & LA after TPF ICT & $\mathrm{RT}$ & \\
\hline & LA resected & CRT & \\
\hline & LA after carbo/paclitaxel ICT & $\mathrm{RT}+\mathrm{P}$ & \\
\hline & Adjuvant after CRT & None & \\
\hline & Local recurrence & BNCT & \\
\hline & Local recurrence & RT & \\
\hline & Local recurrence & $\mathrm{RT}+\mathrm{P}$ & \\
\hline & Local recurrence & Radiosurgery & \\
\hline & Reirradiation & $\mathrm{RT}$ & \\
\hline & $\mathrm{R} / \mathrm{M}$ & carbo/P + pemetrexed & \\
\hline & $\mathrm{R} / \mathrm{M}$ & $\mathrm{TP}$ & \\
\hline & $\mathrm{R} / \mathrm{M} 2 \mathrm{nd}$ & carbo + vinorelbine & \\
\hline
\end{tabular}

LA: locoregionally advanced; R/M: recurrent/metastatic; RT: radiotherapy; P: cisplatin.

T: docetaxel; F: 5-fluorouracil; carbo: carboplatin; ICT: induction chemotherapy.

2nd: second line; NABP: nanoparticle albumin-bound paclitaxel.

BNCT: boron neutron capture therapy; CRT: concurrent chemoradiation; OPC: oropharyngeal cancer.

\subsection{EGFR-Directed Monoclonal Antibodies}

2.1.1. Cetuximab. Cetuximab is the only targeted agent that got approval by the Food and Drug Administration and the European Medicines Agency for the treatment of SCCHN $[8,9]$ and is still under active investigation in this disease [3] (Tables 1 and 2). Cetuximab is a chimeric human/murine IgG1 antibody which binds with higher affinity to the EGFR than the natural ligands EGF and TNF- $\alpha$, thereby disrupting EGFR signaling pathways. Another mechanism that contributes to the antitumor activity of cetuximab is depletion of the targeted receptors from the cell surface. The availability of EGFR on the cell surface is reduced, and the receptor is downregulated $[10,11]$. Finally, cetuximab's construction on an IgG1 framework potentially allows the drug to mediate antibody-dependent cell-mediated cytotoxicity (ADCC) via natural killer (NK) cells and macrophages [12]. Cetuximab is administered once a week at an initial loading of $400 \mathrm{mg} / \mathrm{m}^{2}$ followed by a weekly dose of $250 \mathrm{mg} / \mathrm{m}^{2}$ [8].
The recommended dose was used in the cetuximab studies in SCCHN studies mentioned below, unless stated otherwise.

2.2. Cetuximab in Locoregionally Advanced SCCHN. Bonner et al. $[13,14]$ conducted a multinational, randomized study comparing radiotherapy alone with radiotherapy plus cetuximab in 424 patients with stages III or IV, nonmetastatic, measurable squamous cell carcinoma (SCC) of the oropharynx, hypopharynx, or larynx. Investigators were required to select one of three radiotherapy-fractionation regimens before patient registration: $70.0 \mathrm{~Gy}$ in 35 daily fractions of $2.0 \mathrm{~Gy} /$ fraction, 5 fractions/week for 7 weeks, or two daily fractions of $1.2 \mathrm{~Gy} /$ fraction up to $72.0-76.8 \mathrm{~Gy}$ in 60 64 fractions, 10 fractions/week for 6-6.5 weeks, or a concomitant boost regimen ( $72.0 \mathrm{~Gy}$ in 42 fractions: $32.4 \mathrm{~Gy}$; $1.8 \mathrm{~Gy} /$ fraction, 5 fractions/week for 3.6 weeks followed by a morning dose of $21.6 \mathrm{~Gy}$ in fractions of $1.8 \mathrm{~Gy}, 5$ fractions/week for 2.4 weeks and an afternoon dose of 18.0 Gy in fractions of $1.5 \mathrm{~Gy}, 5$ fractions/week for 2.4 weeks). 
TABLE 2: Targeted agents under investigation in combination with cetuximab.

\begin{tabular}{|c|c|c|c|c|c|}
\hline Trial phase & Associated Compound & $\begin{array}{c}\text { Target/mechanism of } \\
\text { action }\end{array}$ & Disease setting & Administration & Associated treatment \\
\hline \multirow{4}{*}{$\begin{array}{l}\text { Randomized } \\
\text { phase III }\end{array}$} & With or without 0 S1-906 & IGF-1R/IR & $\mathrm{R} / \mathrm{M}$ platinum refractory & po & \\
\hline & With or without E7050 & VEGFR-2; c-MET & $\mathrm{R} / \mathrm{M}$ platinum refractory & po & \\
\hline & $\begin{array}{l}\text { With or without } \\
\text { bevacizumab }\end{array}$ & VEGF & LA & iv & Pemetrexed + RT \\
\hline & $\begin{array}{l}\text { With or without } \\
\text { everolimus }\end{array}$ & mTOR & LA & po & Paclitaxel + P IC \\
\hline \multirow{12}{*}{$\begin{array}{l}\text { Single arm } \\
\text { phase II }\end{array}$} & Sorafenib & $\begin{array}{l}\text { CRAF; BRAF; c-KIT; FLT-3; } \\
\text { VEGFR-2/3; PDGFR- } \beta\end{array}$ & $\mathrm{R} / \mathrm{M}$ & po & \\
\hline & Temsirolimus & mTOR & $\mathrm{R} / \mathrm{M}$ & iv & $\mathrm{P}$ \\
\hline & PX-866 & Phosphoinositide-3-kinase & $\mathrm{R} / \mathrm{M}$ & po & \\
\hline & Everolimus & mTOR & $\mathrm{R} / \mathrm{M}$ & po & Carbo \\
\hline & Bevacizumab & VEGF & $\mathrm{R} / \mathrm{M}$ & iv & \\
\hline & Bevacizumab & VEGF & LA & iv & $(\mathrm{TP}) \rightarrow \mathrm{RT}+\mathrm{P}$ \\
\hline & EMD1201081 & Toll-like receptor 9 agonist & $\mathrm{R} / \mathrm{M} 2 \mathrm{nd}$ & sc & \\
\hline & Lenalidomide & Immunomodulating agent & $\mathrm{R} / \mathrm{M}$; solid tumors & po & \\
\hline & Dasatinib & $\begin{array}{c}\text { BCR-ABL; Src; c-KIT; EPH; } \\
\text { PDGFR } \beta\end{array}$ & LA & po & $\mathrm{RT}( \pm \mathrm{P})$ \\
\hline & BMS-754807 & IGF-1R/IR & solid tumors & po & \\
\hline & Erlotinib & EGFR & $\mathrm{R} / \mathrm{M}$ & po & carbo + paclitaxel \\
\hline & EGFR Antisense DNA & EGFR & & Intratumoral & RT \\
\hline \multirow{9}{*}{ Phase 1} & Everolimus & mTOR & LA & po & \\
\hline & Lenalidomide & Immunomodulating agent & $\mathrm{R} / \mathrm{M}$ & po & $\mathrm{RT}+\mathrm{P}$ \\
\hline & IPI-926 & $\begin{array}{l}\text { Smoothened, hedgehog } \\
\text { pathway }\end{array}$ & $\mathrm{R} / \mathrm{M}$ & po & \\
\hline & VTX-2337 & Toll-like receptor 8 agonist & $\mathrm{R} / \mathrm{M}$ & $\mathrm{sc}$ & \\
\hline & MM-121 & ErbB3 & Advanced tumors & iv & Irinotecan \\
\hline & Lapatinib & EGFR/HER2 & Solid tumors & po & \\
\hline & RO5479599* & HER-3 & HER-3 + tumors & iv & \\
\hline & Sunitinib & $\begin{array}{l}\text { PDGFR } \alpha / \beta \text {; VEGFRl-3; } \\
\text { KIT; FLT3; CSF-1R; RET }\end{array}$ & Local recurrence & po & $\mathrm{RT}$ \\
\hline & Vorinostat & HDACi & LA & po & $\mathrm{RT}+\mathrm{P}$ \\
\hline
\end{tabular}

mTOR: mammalian target of rapamycin; LA: locoregionally advanced; po: per os; iv: intravenously; RT: radiotherapy; EGFR: epidermal growth factor receptor; P: cisplatin; carbo: carboplatin; T: docetaxel; R/M: recurrent/metastatic; OPH: oropharyngeal cancer; c-MET: hepatocyte growth factor receptor; HDACi: histone deacetylase inhibitor; IGF-1R/IR: insulin-like growth factor-l/insulin receptor.

PDGFR $\beta$ : platelet-derived growth factor recpetor $\beta$; BRAF: serine/threonine-protein kinase B-Raf; c-KIT: mast/stem cell growth factor receptor.

*: RO5479599 a lone or with erlotinib or with cetuximab.

Uninvolved nodal areas of the neck were treated with 50 to $54 \mathrm{~Gy}$, depending on the fractionation regimen used. Gross nodal disease received the same dose as the primary tumor. In the group assigned to receive radiotherapy plus cetuximab, cetuximab was initiated one week before radiotherapy at a loading dose of $400 \mathrm{mg} / \mathrm{m}^{2}$, followed by a weekly dose of $250 \mathrm{mg} / \mathrm{m}^{2}$ for the duration of radiotherapy. The median duration of locoregional control (primary endpoint) was 24.4 months in patients treated with cetuximab plus radiotherapy and 14.9 months in patients treated with radiotherapy alone (hazard ratio (HR) for locoregional progression or death, $0.68 ; P=0.005$ ). The one-, two-, and three-year rates of locoregional control achieved with radiotherapy plus cetuximab $(63,50$, and $47 \%)$, were significantly higher than those achieved with radiotherapy alone $(55,41$, and $34 \%$, resp.). Median overall survival (OS) for patients treated with cetuximab and radiotherapy was 49.0 months versus 29.3 months in the radiotherapy-alone group (HR for death: 0.73; $P=0.018)$. Grade $\geq 2$ rash was associated with an improved survival [13]. In this pivotal trial, the addition of cetuximab did not lead to an increased incidence of radiation dermatitis. However, as there is only one randomized phase III trial with cetuximab-based bioradiation as opposed to the abundance of data supporting cisplatin-based concurrent chemoradiation (CRT) $[15,16]$, the latter continues to represent the standard of care for medically fit patients with locoregionally (LA) SCCHN, who can tolerate platinum-based therapy. The addition of cetuximab to cisplatin-based CRT does not further improve the outcome. In Radiation Therapy Oncology Group (RTOG) 0522 [17], 895 evaluable patients 
TABLE 3: Targeted agents under investigation in SCCHN.

\begin{tabular}{|c|c|c|c|c|c|}
\hline Trial phase & Compound & Target/mechanism of action & Disease setting & Administration & Associated treatment \\
\hline \multirow{3}{*}{$\begin{array}{l}\text { Randomized } \\
\text { phase lll }\end{array}$} & INGN 201 & p53 gene & $\mathrm{R} / \mathrm{M}$ & iv & $\mathrm{PF}$ \\
\hline & Bevacizumab & VEGF & $\mathrm{R} / \mathrm{M}$ & iv & platin-based doublet \\
\hline & Reovirus serotype 3 dearing & Virus & $\begin{array}{l}\mathrm{R} / \mathrm{M} \text { platinum } \\
\text { refractory }\end{array}$ & iv & Placebo \\
\hline \multirow{16}{*}{ Phase 11} & Temsirolimus & mTOR & $\mathrm{R} / \mathrm{M}$ & iv & Carbo + paclitaxel \\
\hline & PX-866 & Phosphoinositide-3-kinase & Solid tumors & po & $\mathrm{T}$ \\
\hline & Everolimus & mTOR & $\mathrm{R} / \mathrm{M}$ & po & $(\mathrm{T})$ \\
\hline & Everolimus & mTOR & LA & po & Carbo + paclitaxel \\
\hline & BBI608 & Cancer stem cells & $\begin{array}{c}\text { Advanced } \\
\text { malignancies }\end{array}$ & po & Paclitaxel \\
\hline & Sorafenib & $\begin{array}{l}\text { CRAF; BRAF; c-KIT; FLT-3; } \\
\text { VEGFR-2/3; PDGFR- } \beta\end{array}$ & $\mathrm{R} / \mathrm{M}$ & po & \\
\hline & Cediranib & VEGFR-2/3 & $\mathrm{R} / \mathrm{M}$ & po & \\
\hline & Tadalafil & Phosphodiesterase-5 inhibitor & $\mathrm{R} / \mathrm{M}$ & po & \\
\hline & Fostamatinib & syk & Solid tumors & po & \\
\hline & LY2523355 & Mitotic kinesin Eg5 inhibitor & Solid tumors & iv & \\
\hline & Vorinostat & HDACi & $\mathrm{R} / \mathrm{M}$ & po & Capecitabine \\
\hline & Gossypol & Bcl-2 & $\mathrm{R} / \mathrm{M}$ & po & $\mathrm{T}$ \\
\hline & Pazopanib & $\begin{array}{l}\text { VEGFRl-3; PDGFR } \alpha / \beta \text {; } \\
\text { FGFR1,3,4; KIT; RET }\end{array}$ & $\mathrm{R} / \mathrm{M}$ & po & \\
\hline & ACE-041 & ALK1 & $\mathrm{R} / \mathrm{M}$ second line & sc & \\
\hline & Axitinib & VEGFRl-3; c-KIT; PDGFR & $\mathrm{R} / \mathrm{M}$ & po & \\
\hline & Dacomitinib & Pan-ERBB inhibitor & $\begin{array}{l}\mathrm{R} / \mathrm{M} \text { platinum } \\
\text { refractory }\end{array}$ & po & \\
\hline \multirow{6}{*}{ Phase 1} & MAGE-A3/HPV 16 & Vaccine & $\mathrm{R} / \mathrm{M}$ & & \\
\hline & MLN9708 & Proteasome inhibitor & Solid tumors & po & \\
\hline & 4SC-205 & Mitotic kinesin Eg5 inhibitor & $\begin{array}{c}\text { Advanced } \\
\text { malignancies }\end{array}$ & po & \\
\hline & SAR566658 & HuDS6 + DM4* & $\begin{array}{l}\text { DS6-positive } \\
\text { tumors }\end{array}$ & iv & \\
\hline & MEHD7945A & EGFR/HER3 & $\begin{array}{l}\text { Epithelial } \\
\text { tumors }\end{array}$ & iv & \\
\hline & CUDC-101 & HDACi; EGFR; HER2 & LA & po & $\mathrm{RT}+\mathrm{P}$ \\
\hline
\end{tabular}

RT: radiotherapy; T: docetaxel; P: cisplatin; HDACi: histone deacetylase inhibitor; LA: locoregionally advanced; R/M: recurrent/metastatic.

* Tumor-associated sialoglycotope CA6 (huDS6) conjugated to the cytotoxic maytansinoid DM4.

Syk: spleen tyrosine kinase; po: per os; iv: intravenously.

ALK1: activin receptor-like kinase 1 (ALK1).

with stage III/IV nonmetastatic SCCHN were randomized between chemoradiation ( $72 \mathrm{~Gy}$ in 42 fractions over 6 weeks plus cisplatin $100 \mathrm{mg} / \mathrm{m}^{2}$ on days 1 and 22) or the same regimen plus weekly cetuximab. At the time of the third interim analysis after 337 events and after a median followup of 2.4 years for the surviving patients, the conditional power of the trial becoming positive was below $10 \%$, triggering early reporting. Over $90 \%$ of the patients received the planned two doses of cisplatin in both arms. The 2-year progression-free survival (PFS), (primary endpoint) was $64.3 \%$ with chemoradiation and $63.4 \%$ with chemoradiation plus cetuximab (HR: 1.05; 95\% confidence interval (CI): 0.84 $1.29 ; P=0.67)$. The 2 -year OS was 79.7 and $82.6 \%$, respectively (HR: 0.87 ; $95 \%$ CI: $0.66-1.15 ; P=0.17$ ). The estimated 2-year locoregional relapse rate was 19.8 and $24.5 \%$, respectively $(P=0.92)$. The 2 -year distant metastasis rate was 12 and $7.6 \%$, respectively $(P=0.07)$. Overall, there was no difference regarding acute grade $3 / 4$ acute toxicities between both arms. However, grade $3 / 4$ mucositis ( 43 versus $33 \%$ ) and in-field dermatitis ( 25 versus $15 \%$ ) was more common with the addition of cetuximab. Grade 3/4 dermatitis outside the radiation field occurred in $19 \%$ of the patients treated with cetuximab.

The TREMPLIN trial [18] is a randomized phase II study in patients with SCC of the larynx or hypopharynx suitable for total laryngectomy. After three 3 weekly cycles of TPF (docetaxel $75 \mathrm{mg} / \mathrm{m}^{2}$ and cisplatin $75 \mathrm{mg} / \mathrm{m}^{2}$ on day 1 followed by 5 -FU $750 \mathrm{mg} / \mathrm{m}^{2} /$ day, days $1-5$ ), patients who obtained at least a partial response ( $82 \%$ of the patients) were randomized to receive radiotherapy ( $70 \mathrm{~Gy}$ in 35 fractions 
TABLE 4: EGFR-directed targeted agents under investigation in SCCHN (other than cetuximab).

\begin{tabular}{|c|c|c|c|c|}
\hline Trial phase & Compound & Disease setting & Associated treatment & Comparator \\
\hline \multirow{9}{*}{ Phase III } & Monoclonal Antibodies & & & \\
\hline & Nimotuzumab & LA resected & $\mathrm{RT}+\mathrm{P}$ & Placebo \\
\hline & & LA & RT & None \\
\hline & Zalutumumab & nonmetastatic & $\mathrm{RT}( \pm \mathrm{P})$ & None \\
\hline & Tyrosine kinase inhibitors & & & \\
\hline & Lapatinib* & resected high risk & & Placebo \\
\hline & Afatinib* & LA and NED after RT $+\mathrm{P}(+\mathrm{S})$ & & Placebo \\
\hline & & $\mathrm{LA}$ after resection and $\mathrm{RT}+\mathrm{P}$ & & Placebo \\
\hline & & R/M platinum-refractory & & Methotrexate \\
\hline \multirow{3}{*}{ Randomized phase II } & Tyrosine kinase inhibitors & & & \\
\hline & Erlotinib & LA & $\mathrm{RT}+\mathrm{P}$ & None \\
\hline & Erlotinib & $\mathrm{R} / \mathrm{M}$ & $\mathrm{TP}$ & Placebo \\
\hline \multirow{12}{*}{ Phase II } & Monoclonal antibodies & & & \\
\hline & Panitumumab & $\mathrm{R} / \mathrm{M}$ & Paclitaxel & \\
\hline & Nimotuzumab & LA & $\mathrm{RT}+\mathrm{P}$ & \\
\hline & & LA & (T) PF ICT & \\
\hline & SYM- $004^{* * *}$ & $\mathrm{R} / \mathrm{M}$ platinum-refractory & & \\
\hline & Tyrosine kinase inhibitors & & & \\
\hline & Lapatinib* & LA & RT & \\
\hline & Lapatinib* & $\mathrm{R} / \mathrm{M}$ & Capecitabine & \\
\hline & Erlotinib & LA & $\mathrm{RT}(+\mathrm{T})$ & \\
\hline & & LA resected & $\mathrm{RT}+\mathrm{P}$ & \\
\hline & & Local recurrence/2nd primary & $\mathrm{RT}+$ pemetrexed & \\
\hline & & Local recurrence & & \\
\hline \multirow{3}{*}{ Phase I } & Monoclonal antibodies & & & \\
\hline & ABT- $806^{* *}$ & Solid tumors & & \\
\hline & R05083945 or cetuximab & Operable & & \\
\hline
\end{tabular}

NED: no evidence of disease; S: lymph node resection.

CRT: concurrent chemoradiation; ICT: induction chemotherapy.

T: docetaxel; P: cisplatin.

${ }^{*}$ Dual EGFR/HER2 inhibitor. ${ }^{* *}$ Targets also EGFRvIII. ${ }^{* * *}$ Recombinant IgG1 antibody product consisting of two antibodies against EGFR.

over 7 weeks) either with cisplatin $100 \mathrm{mg} / \mathrm{m}^{2}$ on days 1,22 , and 43 or with weekly cetuximab. The treatment compliance was better in the cetuximab arm with $71 \%$ of the patients receiving all planned cetuximab administrations. Forty-three percent of the patients received three cycles of cisplatin, and $83 \%$ received 2 cycles. There was no difference in grade $3 / 4$ mucosal toxicity, but grade $3 / 4$ in-field dermatitis was more frequently observed with cetuximab (57 versus $26 \%$; $P<0.001)$. Grade 1 renal dysfunction at last evaluation was observed in $22.4 \%$ of the patients treated with cisplatin. The larynx preservation rate 3 months after treatment (primary endpoint) was 95\% with cisplatin versus 93\% with cetuximab. The locoregional failure rate after a median followup of 36 months was $11.7 \%$ with cisplatin and $21.4 \%$ with cetuximab. However, more salvage laryngectomies were performed in the cetuximab arm, resulting in a similar ultimate locoregional failure rate in the two arms $(10 \%$ versus $8.9 \%$ ). The 2-year laryngoesophageal dysfunction-free survival was $79 \%$ with cisplatin versus $71 \%$ with cetuximab $(P=0.3)$.
Seiwert et al. [19] randomized 110 patients with LA SCCHN, who had received 2 cycles of carboplatin, paclitaxel, and cetuximab as induction chemotherapy, between weekly cetuximab in combination with either 5-FU, hydroxyurea, and hyperfractionated week-on week-off radiotherapy (7274 Gy) (CetuxFHX), or cisplatin, accelerated radiation with concomitant boost (CetuxPX) (72 Gy). After a median followup of 21 months, 2-year OS rates were $89.5 \%$ with CetuxFHX and 91.4\% with CetuxPX arm. Two-year PFS rates were $82.3 \%$ and $89.7 \%$, respectively $(P=0.18)$. Grade $\geq 3$ mucositis was present in $91.1 \%$ (CetuxFHX) and $94.3 \%$ (CetuxPX) of patients; grade $\geq 3$ dermatitis in $82.1 \%$ and $50.9 \%$, respectively. Ninety-five percent of patients completed therapy, demonstrating that cetuximab can be incorporated safely in both CRT platforms.

Argiris et al. [20] enrolled 32 patients in a phase I study combining pemetrexed, cetuximab and radiotherapy in poor prognosis head and neck cancer. Cohort A included patients who had not been previously irradiated, while cohort $\mathrm{B}$ included patients who had received prior irradiation. 
Pemetrexed was administered on days 1, 22, and 43. The maximum tolerated dose (MTD) of pemetrexed was $500 \mathrm{mg}$ in cohort A and $350 \mathrm{mg} / \mathrm{m}^{2}$ in cohort B. Grade 3/4 neutropenia was common (50\% in cohort $\mathrm{A}$ and $33 \%$ in cohort $\mathrm{B}$ ) and febrile neutropenia was the most frequent doselimiting toxicity. Prophylactic antibiotics are recommended. Grade $3 / 4$ mucositis was observed in 8 of the 9 patients treated at the MTD in cohort A [20].

In Eastern Cooperative Oncology Group (ECOG) E2303 [21], 63 patients with resectable stage III/IV SCCHN, were treated with 6-week cycles of paclitaxel, carboplatin at an AUC of 2 and cetuximab, followed by CRT (weekly paclitaxel, $30 \mathrm{mg} / \mathrm{m}^{2}$, carboplatin AUC 1, and cetuximab). If at week 14 , after a radiation dose of $50 \mathrm{~Gy}$, tumor was still present on biopsy, salvage surgery was performed. In case of a negative biopsy ( $91 \%$ of the patients), CRT was continued to a total dose of $68-72$ Gy. Two-year PFS and OS rate were 82 and $66 \%$, respectively. A local recurrence occurred in $17.5 \%$ of the patients. Jordan et al. [22] treated 152 T3-T4 SCCHN patients with three 3-week cycles of TPF (docetaxel $75 \mathrm{mg} / \mathrm{m}^{2}$ on day 1 , cisplatin $35 \mathrm{mg} / \mathrm{m}^{2}$ on days 1 and 2 , and 5 -FU $750 \mathrm{mg} / \mathrm{m}^{2} /$ day, as a continuous infusion, days 15 , with pegfilgrastim support) followed by chemoradiation ( $63 \mathrm{~Gy}$ in 35 fractions of $1.8 \mathrm{~Gy}$ over 7 weeks and weekly cisplatin, $40 \mathrm{mg} / \mathrm{m}^{2}$ ) plus weekly cetuximab. The complete response rate in the 142 patients, who were evaluated after the completion of therapy, was $57 \%$. Grade $3 / 4$ toxicities occurred in $34 / 142$ patients (24\%). In 15 patients, CRT had to be interrupted due to dermatitis.

2.2.1. Maintenance Treatment. Ferris et al. [23] treated 34 LA SCCHN patients with three 3-weekly cycles of cisplatin $75 \mathrm{mg} / \mathrm{m}^{2}$ and docetaxel $75 \mathrm{mg} / \mathrm{m}^{2}$ plus weekly cetuximab followed by CRT (70 Gy in 2 Gy fractions over 7 weeks, weekly cisplatin $30 \mathrm{mg} / \mathrm{m}^{2}$ ) plus weekly cetuximab, followed by weekly cetuximab maintenance for 6 months. The 3-year PFS rate was $70 \%$.

Mesia et al. [24] studied the role of cetuximab maintenance therapy in patients with LA SCC of the oropharynx. Ninety-one patients were randomized. Patients in group A were treated concomitant radiotherapy, 69.9 Gy in 28 days, plus weekly cetuximab. Patients in group B received an additional 12-week administrations of cetuximab. The locoregional control rate at 1 year (primary endpoint) was $56.8 \%$ with bioradiation and $60.5 \%$ with bioradiation followed by cetuximab maintenance. At 1 year, event-free survival rates were 55.6 and $60.9 \%$, respectively, and OS rates were 75.6 and $87 \%$, respectively.

\subsection{Cetuximab in Recurrent/Metastatic SCCHN}

2.3.1. First-Line Treatment. In the EXTREME trial (Erbitux in First-Line Treatment of Recurrent or Metastatic Head and Neck Cancer) [25], 442 patients with previously untreated R/M SCCHN were randomized to receive cisplatin $100 \mathrm{mg} / \mathrm{m}^{2}$ or carboplatin at an area under the curve (AUC) of $5 \mathrm{mg} / \mathrm{mg} / \mathrm{min}$ as an 1 -hour infusion, followed by 5 -FU $1000 \mathrm{mg} / \mathrm{m}^{2}$ day for 4 days as a continuous infusion every
3 weeks for a maximum of 6 cycles, either alone or in combination with cetuximab. The use of cisplatin or carboplatin was at the discretion of the investigator. After a maximum of six cycles of chemotherapy, patients in the cetuximab group who had at least stable disease received cetuximab monotherapy until disease progression or unacceptable toxic effects, whichever occurred first. Cross-over was not allowed. The median overall survival (primary endpoint) was 10.1 months (95\% CI: 8.6-11.2) in the cetuximab group and 7.4 months (95\% CI: 6.4-8.3) in the chemotherapy-alone group (HR for death: $0.80 ; 95 \% \mathrm{CI}: 0.64-0.99 ; P=0.04$ ). The median followup was 19.1 months in the cetuximab group and 18.2 months in the chemotherapy-alone group. Median PFS was 5.6 months and 3.3 months for the combined group and the chemotherapy alone group, respectively (HR for progression: 0.54 ; 95\% CI: $0.43-0.67 ; P<0.001)$. The overall response rate (ORR) was 36 and $20 \%$, respectively (odds ratio (OR): 2.33; $P<0.001$ ), and the disease control rate (DCR) was 80 and 60\%, respectively (OR: 2.88; $P<$ $0.001)$. Among the 100 patients who received cetuximab as maintenance treatment, the median PFS was 12 weeks from the start of maintenance treatment. The safety profile of the study treatment was consistent with that expected for the agents used, with no significant difference in the incidence of grades 3 or 4 adverse events between treatment arms. However, there were 9 cases of sepsis in the cetuximab group, as compared with 1 case in the chemotherapy-alone group $(P=0.02)$, and there were 11 cases of hypomagnesemia in the cetuximab group, as compared with 3 cases in the chemotherapy-alone group $(P=0.05)$. Grade 3 skin reactions were seen in $9 \%$ of the patients who received cetuximab. There were four grade 3 and two grade 4 infusionrelated reactions after cetuximab [25]. ECOG [26] randomized $117 \mathrm{R} / \mathrm{M}$ SCCHN patients to receive cisplatin $100 \mathrm{~m} / \mathrm{m}^{2}$ every 4 weeks plus either weekly cetuximab (group A) or placebo (group B). Primary endpoint was PFS. Median PFS was 4.2 months in arm A and 2.7 in arm B (HR: 0.78; 95\% CI: $0.54-1.12 ; P=0.09)$. Median OS was 9.2 months in arm $A$ and 8.0 months in arm B $(P=0.21)$. The ORR was $26 \%$ and $10 \%$, respectively $(P=0.03)[26]$.

Hitt et al. [27] treated 46 patients with weekly cetuximab and paclitaxel $80 \mathrm{mg} / \mathrm{m}^{2}$ as first-line regimen for recurrence of metastatic SCCHN. The ORR and DCR were 54 and $80 \%$, respectively. Median PFS and OS were 4.2 and 8.1 months, respectively. Common grade $3 / 4$ adverse events were acnelike rash (24\%), asthenia (17\%), and neutropenia (13\%) [27]. In Groupe d'Oncologie Radiothérapie Tête Et Cou (GORTEC) 2008-03 [28], 54 patients who had not received prior chemotherapy for R/M SCCHN were treated with docetaxel $75 \mathrm{mg} / \mathrm{m}^{2}$ and cisplatin $75 \mathrm{mg} / \mathrm{m}^{2}$ every 3 weeks and weekly cetuximab, up to 4 cycles, followed by cetuximab maintenance in the absence of disease progression. Patients received prophylactic lenograstim. The ORR and DCR were 51.9 and $96.1 \%$, respectively. At time of reporting, $65 \%$ of the patients were still alive, and median OS exceeded 11 months. High EGFRvIII and amphiregulin expression levels identify SCCHN patients who are less likely to benefit from combination treatment with cetuximab and docetaxel [29]. 
2.3.2. Second-Line Treatment. Three phase II trials examined the role of cetuximab in platinum-refractory or platinumresistant disease [30-33]. Responses (10-13\%) were observed irrespective of reintroducing the originally used platinum compound to which they had become refractory or resistant. The survival of around 6 months achieved with cetuximab in platinum-refractory disease was found similar to that seen in first-line therapy in R/M-SCCHN and represented an increase in survival of 2.5 months compared with platinum-refractory historical controls [34]. Based on these results and particularly considering the fact that about $50 \%$ of the patients showed disease control, cetuximab monotherapy seems to be an option for patients with R/M SCCHN who have progressed on platinum-based chemotherapy.

Fury et al. [35] randomized 61 patients, who had received $\leq 2$ prior cytotoxic chemotherapy regimens for R/M SCCHN to receive cetuximab every 2 weeks at either 500 (A) or $750 \mathrm{mg} / \mathrm{m}^{2}$ (B). The ORR was $11 \%$ in both arms. PFS was also similar (65 days versus 57 days). Median OS was 8.1 months. Cetuximab $500 \mathrm{mg} / \mathrm{m}^{2}$ every 2 weeks seemed to yield similar efficacy and tolerability as conventional weekly dosing for patients with R/M SCCHN. However, it is unclear how many of the patients in this study had platinum-refractory disease. There is no apparent efficacy advantage associated with dose escalation to $750 \mathrm{mg} / \mathrm{m}^{2} \mathrm{Q} 2 \mathrm{~W}$.

2.3.3. Zalutumumab. Zalutumumab is a human IgG1 monoclonal antibody targeting EGFR. Machiels et al. [36] randomly allocated 286 eligible incurable SCCHN in a $2: 1$ ratio to receive either zalutumumab plus best supportive care (zalutumumab group) or best supportive care with optional methotrexate (control group). Eligible were patients with progressive disease according to RECIST confirmed by an independent review committee during or within 6 months after the failure of platinum-based chemotherapy (at least two cycles of cisplatin $\left[\geq 60 \mathrm{mg} / \mathrm{m}^{2}\right.$ per cycle] or carboplatin $\left[\geq 250 \mathrm{mg} / \mathrm{m}^{2}\right.$ per cycle] with an interval between the cycles of $<4$ weeks). Also eligible were patients with platinum intolerance which was defined as discontinuation or dose reduction of platinum-based chemotherapy due to adverse or toxic effects, irrespective of response. The dose of zalutumumab was titrated according to rash. Patients were given an initial loading dose of $8 \mathrm{mg} / \mathrm{kg}$ followed up by two week doses of $4 \mathrm{mg} / \mathrm{kg}$ by intravenous infusion in $1 \mathrm{~h}$. After the first three administrations, in patients with no rash or grade $1 \mathrm{rash}$, the dose was increased by $4 \mathrm{mg} / \mathrm{kg}$ every 2 weeks up to a maximum dose of $16 \mathrm{mg} / \mathrm{kg}$. Patients with grade 2 rash remained at the same dose. Treatment was withheld from patients with grade 3 rash until rash resolved to grade 1 . Seventy-two percent of the control patients received methotrexate from the initiation of the trial, and a further $6 \%$ started methotrexate during the trial. Median OS (primary endpoint) was 6.7 months (95\% CI: 5.8-7.0) in the zalutumumab group and 5.2 months (95\% CI: 4.1-6.4) in the control group (hazard ratio (HR) for death, stratified by WHO performance status: 0.77 ; $97.06 \%$ CI: $0.57-1.05$; unadjusted $P=0.0648$ ). Progression-free survival was longer in the zalutumumab group than in the control group (HR for progression or death, stratified by WHO performance status:
0.63; 95\% CI: $0.47-0.84 ; P=0.0012)$. The most common grade $3 / 4$ adverse events were rash $(21 \%$ of patients in the zalutumumab group versus none in the control group), anemia (6\% and $5 \%$, resp.), and pneumonia (5\% and $2 \%$, resp.). Grade 3/4 infections occurred in $15 \%$ of the patients in the zalutumumab group and $9 \%$ in the control group [36].

2.3.4. Panitumumab. Panitumumab is a fully human IgG2 EGFR-directed antibody. Its pharmacokinetic profile allows a convenient three-week administration. In the SPECTRUM trial (Study of Panitumumab Efficacy in Patients With Recurrent and/or Metastatic Head and Neck Cancer), [37] 657 patients were randomized between cisplatin $100 \mathrm{mg} / \mathrm{m}^{2}$ on day 1 , followed by 5 -fluorourcacil $1000 \mathrm{mg} / \mathrm{m}^{2} /$ day for 4 days or the same chemotherapy plus panitumumab $9 \mathrm{mg} / \mathrm{kg}$ administered on day 1 . Cycles were repeated every 3 weeks up to a maximum of 6 cycles. Patients receiving panitumumab without progression after 6 cycles could continue panitumumab monotherapy until progression. Patients were allowed to switch from cisplatin to carboplatin (AUC 5) during treatment for specific cisplatin-related toxicities, such as grade $\geq 2$ neurotoxicity or a drop in creatinine clearance to $<50 \mathrm{~mL} / \mathrm{min}$. Overall survival was the primary endpoint. The median OS in the combined arm was 11.1 months compared to 9.0 months in the chemotherapy alone arm $(\mathrm{HR}=0.87$; 95\% CI: $0.73-1.05$; $P=0.14$ ). However, there was a statistically significant difference in response rate (36\% versus $25 \%$; $P=0.007$ ) and PFS (median 5.8 months versus 4.6 months; $\mathrm{HR}=0.78 ; 95 \% \mathrm{CI}: 0.66-0.92 ; P=0.004)$ in favour of the panitumumab-containing arm. Although the SPECTRUM trial failed to meet its primary endpoint, the results are nevertheless consistent with the outcome of the EXTREME trial.

2.3.5. Nimotuzumab. Nimotuzumab is a humanized EGFR targeting monoclonal antibody which was studied in multiple phase II trials. A weekly fixed dose of $200 \mathrm{mg}$ was established as recommended dose for use in combination with radiotherapy in LA SCCHN. No grade $3 / 4$ adverse events were reported in a pilot study of weekly nimotuzumab $(200 \mathrm{mg}$ ), radiotherapy (66 Gy in 33 fractions/2 Gy per fraction over 6.5 weeks) and weekly cisplatin $\left(40 \mathrm{mg} / \mathrm{m}^{2}\right)$ in 17 patients with LA SCCHN [38]. Rodríguez et al. [39] enrolled 106 patients with inoperable LA SCCHN in a double blind, randomized phase II trial. The primary endpoint of the trial was the complete response rate, which was 59.5\% with nimotuzumab versus $34.2 \%$ with placebo $(P=0.028)$. Babu et al. [40] also conducted a randomized phase II trial in patients with LA SCCHN. Ninety-two patients were enrolled, and 76 were evaluable. Patients included in group A were treated with radiation (60-66 Gy) with or without nimotuzumab. At 48 months of followup, OS was $34 \%$ with RT plus nimotuzumab versus $13 \%$ with radiotherapy alone.

Patients included in group B were treated with CRT (60-66 Gy plus weekly cisplatin at a dose of $50 \mathrm{mg}$ ) with or without weekly nimotuzumab. At 48 months of followup, OS rate was $47 \%$ with CRT plus nimotuzumab versus $21 \%$ with CRT $(P=0.01)$. 
2.4. Tyrosine Kinase Inhibitors. Tyrosine kinase inhibitors which have been tested in SCCHN include gefitinib and erlotinib, which are reversible specific EGFR TKIs, lapatinib, a reversible dual EGFR/Her2 TKI, afatinib, an irreversible dual EGFR/Her2 TKI, and PF-00299804, a potent irreversible pan-HER TKI.

\subsubsection{Gefitinib and Erlotinib}

Recurrent/Metastatic SCCHN. Argiris et al. [41] planned to randomize 330 patients to receive docetaxel $35 \mathrm{mg} / \mathrm{m}^{2}$ on days 1,8 , and 15 every 28 days either plus placebo or in combination with gefitinib $250 \mathrm{mg} /$ day. The data monitoring committee recommended early stopping of enrollment after inclusion of 270 patients because there was $<5 \%$ chance to meet the primary endpoint (overall survival). Eligible were patients who were previously treated with chemotherapy for R/M SCCHN (73\% of the patients) and patients previously untreated for R/M SCCHN either with a poor performance status (ECOG 2) or in case of relapse within 6 months after chemotherapy given as part the primary treatment with curative intent. Median OS was 6.8 months with docetaxel plus placebo versus 6.2 months with docetaxel plus gefitinib (HR 0.99; 95\% CI: $0.75-1.31 ; P=0.97$ ). The time to progression was significantly longer with the addition of gefitinib (median 3.5 months versus 2.1 months; HR 0.69; 95\% CI: $0.49-0.99 ; P=0.047$ ). In the IMEX trial [42], $486 \mathrm{R} / \mathrm{M}$ SCCHN patients were randomly assigned to oral gefitinib $250 \mathrm{mg} /$ day, gefitinib $500 \mathrm{mg} /$ day, or methotrexate $40 \mathrm{mg} / \mathrm{m}^{2}$ intravenously weekly. Physicians and patients were blinded to the gefitinib dose. Two coprimary analyses compared OS between each gefitinib dose and methotrexate. Patients were stratified into two groups: group A $(n=256)$ consisted of patients who had stable or progressive disease after at least two cycles of platinum-based chemotherapy for recurrent disease; group $\mathrm{B}(n=230)$ consisted of patients who were considered unsuitable for platinum-containing chemotherapy. Neither gefitinib $250 \mathrm{mg}$ /day nor gefitinib $500 \mathrm{mg} /$ day improved OS compared with methotrexate (HR: 1.22; 95\% CI: 0.95-1.57; $P=0.12$; HR: 1.12 ; 95\% CI: $0.87-$ $1.43 ; P=0.39$, resp.). Median OS was 5.6, 6.0, and 6.7 months in the gefitinib $250 \mathrm{mg} /$ day, gefitinib $500 \mathrm{mg} /$ day, and methotrexate groups, respectively. In group A, OS was significantly longer with methotrexate (HR for death: gefitinib $250 \mathrm{mg}$ versus methotrexate: $1.62 ; P=0.01$; gefitinib $500 \mathrm{mg}$ versus methotrexate: $1.5 ; P=0.02$ ). Tumor hemorrhage-type events were more common with gefitinib (250 and $500 \mathrm{mg}$ ) than with methotrexate $(8.9 \%, 11.4 \%$, and $1.9 \%$, resp.). The most common adverse events were rash, diarrhea, cancer pain, nausea, and vomiting with gefitinib, and stomatitis, nausea, and constipation with methotrexate.

The OS with gefitinib in the IMEX trial was similar to what was observed in earlier uncontrolled phase II studies with gefitinib or erlotinib [43-46]. Dose escalation of gefitinib adaptive to skin toxicity grade did not improve response rate in a phase II trial conducted by Perez et al. [47].

Locoregionally Advanced SCCHN. William Jr. et al. [48] randomized 34 patients with resectable SCCHN to receive erlotinib daily for 2 to 8 weeks prior to surgery at standard $(150 \mathrm{mg})$ or high doses $(200 \mathrm{mg}$ in never/former smokers, and $300 \mathrm{mg}$ in current smokers). There were no grade 4 toxicities or erlotinib-related surgical complications. Response rates were documented in $18 \%$ and $29 \%$ of the patients in the low-and high-dose arms, respectively, suggesting that a subgroup of previously untreated SCCHN is highly sensitive to EGFR tyrosine kinase inhibition.

Hayes et al. [49] randomly assigned 128 patients with LA SCCHN to receive either cisplatin $100 \mathrm{mg} / \mathrm{m}^{2}$ on days 1,22 , and 43 combined with 70 Gy of radiotherapy (arm A) or the same treatment plus $150 \mathrm{mg}$ of erlotinib starting one week before CRT and continued until the completion of radiotherapy (arm B). Serious adverse events were observed in $33 \%$ and $32 \%$ of the patients in arm A and B, respectively. Most common serious adverse events were nausea, vomiting, and dehydration and accounted for $30 \%$ of all SAEs reported, with no difference between arms. Efficacy data are pending. Gregoire et al. [50] enrolled 226 patients in a randomized phase II trial testing the value of gefitinib during and/or after CRT in LA SCCHN. Patients received either placebo during CRT followed by adjuvant placebo, or gefitinib $250 \mathrm{mg}$ or $500 \mathrm{mg} /$ day during CRT followed by placebo, gefitinib $250 \mathrm{mg}$ or $500 \mathrm{mg} /$ day during and after CRT, or placebo during CRT followed by adjuvant gefitinib at a dose of $250 \mathrm{mg}$ or $500 \mathrm{mg} /$ day. Adjuvant therapy was administered for a maximum of 2 years. There was no difference in 2-year local disease control rate (primary endpoint) between the 7 treatment arms. Soulieres et al. [51] evaluated the toxicity and recommended dose for adjuvant erlotinib after definitive CRT for LA SCCHN. No dose limiting toxicities were observed at a daily dose of 100 or $150 \mathrm{mg}$ for 6 months. At the $150 \mathrm{mg}$ dose, $46 \%$ of the patients received $\geq 90 \%$ dose intensity. The approach can be considered for a phase III trial.

2.4.2. Dual EGFR/Her2- and Pan HER-Inhibitors. Encouraging preliminary results in R/M SCCHN after failure of a platinum-containing therapy were reported with afatinib, a dual EGFR/Her2 irreversible tyrosine kinase inhibitor, which was compared to single-agent cetuximab in a randomized phase II study. The overall response rate with afatinib compared favorably to the ORR with cetuximab [52]. Harrington et al. [53] enrolled 67 patients into a randomized, placebocontrolled, phase II trial, exploring the potential benefit of adding lapatinib to CRT in patients with LA SCCHN. Lapatinib $(1500 \mathrm{mg} /$ day $)$ or placebo were started 1 week before CRT (70 Gy in 35 fractions over 7 weeks plus cisplatin $100 \mathrm{mg} / \mathrm{m}^{2}$ on days 1,22 , and 43) and continued during and after CRT until disease progression. The addition of lapatinib did not impair the timely administration of CRT and did not lead to an increase in mucositis and radiation dermatitis. The complete response rate at 6 months after treatment (primary endpoint) was $36 \%$ with placebo and $53 \%$ with lapatinib. The PFS rates at 12 months were 45 and 59\%, respectively. Del Campo et al. [54] treated 107 patients with LA SCCHN with either lapatinib or placebo for 2-6 weeks prior to CRT. The overall response rate before CRT in the 40 patients who received $>4$ weeks of lapatinib was $17 \%$. 
Siu et al. [55] enrolled 69 patients in a phase II study with PF-00299804 at a dose of $45 \mathrm{mg}$ QD, in previously untreated R/M SCCHN. Grade 3 adverse events were diarrhea (16\%), fatigue (9\%), acneiform dermatitis (7\%), and hand-foot reaction (4\%). The ORR and DCR were 12.7 and $60 \%$, respectively. Median PFS and OS were 2.8 and 8.3 months, respectively.

\section{VEGFR-Directed Therapies}

A meta-analysis conducted by Kyzas et al. [56] demonstrated that VEGF protein overexpression, as detected with immunohistochemistry, is associated with a worse OS in patients with SCCHN.

3.1. Bevacizumab. Bevacizumab is a humanized IgG1 monoclonal antibody that binds selectively to all isoforms of human VEGF and neutralizes the biologic activities of VEGF by blocking the binding of VEGF to its receptors on the surface of endothelial cells. Bevacizumab enhances the activity of chemotherapy in SCCHN xenografts $[57,58]$.

Argiris et al. [59] combined pemetrexed $500 \mathrm{mg} / \mathrm{m}^{2}$ and bevacizumab $15 \mathrm{mg} / \mathrm{kg}$ given intravenously every 21 days until disease progression in 40 patients presenting with previously untreated R/M SCCHN. The median TTP (primary endpoint) was 5 months, and the median OS was 11.3 months. In 37 evaluable patients, the ORR was $30 \%$, and the DCR was $86 \%$. Grade $\geq 3$ bleeding events occurred in $6 / 40$ patients (15\%) and was fatal in $2(5 \%)$ [59]. Bevacizumab, $10 \mathrm{mg} / \mathrm{kg}$, administered on day 1 of each 2 -week cycle, can be safely combined with FHX CRT regimen, consisting of five 2-week cycles of hydroxyurea $500 \mathrm{mg}$ orally bid, 5-FU $600 \mathrm{mg} / \mathrm{m}^{2} /$ day administered as a continuous infusion, and radiotherapy, 1.5 Gy bid for 5 days followed by 9 days without therapy (FHX), in patients with poor prognosis SCCHN [60]. Salama et al. [61] conducted a randomized phase II study evaluating the impact of adding bevacizumab (B) to the FHX regimen. Eligible were patients with T1-3, N0-1 and T4, N0-1 SCCHN. The study was terminated early after enrollment of 26 patients following unexpected locoregional progression. All locoregional progression occurred in T4 tumors randomized to BFHX. Two patients receiving BFHX died during therapy, and one died shortly after therapy. Twoyear OS was $89 \%$ in patients treated with FHX and 58\% in patients treated with BFHX. These unexpected findings are not well understood and could be due to chance, given the small sample size. Harari et al. [62] demonstrated the safety and feasibility of combining CRT (70 Gy in 33 fractions and weekly cisplatin, $30 \mathrm{mg} / \mathrm{m}^{2}$ ) with bevacizumab weeks $-3,1$, 4 , and 7 with dose escalation from 5 to 10 to $15 \mathrm{mg} / \mathrm{kg}$ in 10 patients with LA SCCHN. Several patients manifested tumor regression following administration of bevacizumab alone. No dose-limiting toxicities (DLTs) were observed.

3.2. Tyrosine Kinase Inhibitors. Sorafenib and sunitinib are oral inhibitors of multiple kinases including the receptor tyrosine kinases of vascular endothelial growth factor (VEGF) receptor. Phase II data with both agents in R/M SCCHN are extremely disappointing. Elser et al. [63] treated 27 patients with $\mathrm{R} / \mathrm{M}$ SCCHN or nasopharyngeal carcinoma (7 patients), who had received $\leq 1$ chemotherapy for recurrent or metastatic disease with sorafenib $400 \mathrm{mg}$ twice daily on a continuous basis. The treatment was well tolerated with few grade 3 or 4 toxicities. However, anticancer activity was modest. One patient achieved a partial response (3.7\%). Disease control rate was $40.7 \%$. The median TTP was 1.8 months, and median OS was 4.2 months. The same regimen was evaluated in the Southwest Oncology Group study S0420 [64], which enrolled 41 R/M SCCHN patients who had not received prior chemotherapy for R/M disease. The overall confirmed response rate was a mere $2 \%$. However, the estimated median PFS was 4 months, and the estimated median OS was 9 months. In the GORTEC 2006-01 study [65], 38 patients with R/M SCCHN received sunitinib $37.5 \mathrm{mg} /$ day on a continuous basis. Forty-five percent and $3 \%$ of the patients had received one and two prior chemotherapy regimens for $\mathrm{R} / \mathrm{M}$ disease, respectively. Local complications, including the appearance or worsening of tumor skin ulceration or tumor fistula, were recorded in $39.5 \%$ of the patients, and a fatal arterial bleeding in the head and neck region occurred in $10.5 \%$ of the patients. The ORR and DCR were 2.6 and 50\%, respectively. Median PFS and OS were 2 and 3.4 months, respectively. Fountzilas et al. [66] treated $17 \mathrm{R} / \mathrm{M}$ SCCHN patients with sunitinib $50 \mathrm{mg}$ per day administrated in 4-week cycles followed by a rest period of 2 weeks as first-line treatment for $\mathrm{R} / \mathrm{M}$ disease and observed no objective responses. Disease control rate was $18 \%$, median TTP was 2.3 months, and median OS was 4 months. The same intermittent sunitinib regimen was used by Choong et al. [67] who observed an ORR of $4.5 \%$ and a DCR of $27.3 \%$. Sabichi et al. [68] combined paclitaxel, carboplatin AUC 6, administered every 3 weeks, and sorafenib $400 \mathrm{mg}$ bid, days $2-19$, in patients with R/M SCCHN. Twenty-eight patients were enrolled and 22 were evaluable for response. The ORR and DCR were 68 and 91\%, respectively. Vandetanib is an inhibitor of vascular endothelial growth factor receptor-2 (VEGFR-2), EGFR, and rearranged during transfection (RET) tyrosine kinases. It restores HNSCC cells' sensitivity to cisplatin and radiation in vitro and in vivo [69]. As a single agent, it has antiproliferative effects on SCCHN cells in vitro and inhibits tumor growth in nude mice orthotopically injected with human SCCHN cells [70]. Vandetanib can be safely combined with radiotherapy $(2.2 \mathrm{~Gy} / \mathrm{d}, 5$ days/week up to a total dose of $66 \mathrm{~Gy}$ ) or radiotherapy ( $2 \mathrm{~Gy} / \mathrm{d}, 5$ days/week up to a total dose of $70 \mathrm{~Gy}$ ) plus weekly $30 \mathrm{mg} / \mathrm{m}^{2}$ of cisplatin [71].

\section{Other Targets}

4.1. Heat-Shock Protein 90. Heat-shock protein 90 (HSP90) is a protein which chaperones multiple client oncoproteins involved in tumor progression. Okui et al. [72] investigated the antitumor effect of the novel HSP90 inhibitor NVPAUY922 against oral SCC (OSCC). NVP-AUY922 inhibited the proliferation of OSCC cells in vitro and induced a robust antitumor response and suppressed p-Akt and VEGF expression in an HSC-2 xenograft model. 
4.2. Sirtuin. Several sirtuin family members (SIRT1-7) function either as nicotinamide adenine dinucleotide (NAD)dependent deacetylases or as ADP-ribosyl transferases and are involved in carcinogenesis [73]. Alhazzazi et al. [74] demonstrated that SIRT3 is overexpressed in OSCC in vitro and in vivo and that SIRT3 downregulation inhibits OSCC cell growth and proliferation and increased OSCC cell sensitivity to radiation and cisplatin treatments in vitro.

4.3. Histone Deacetylase. Histone deacetylases are enzymes involved in remodeling of chromatin by deacetylating the lysine residues and play a pivotal role in epigenetic regulation of gene expression. There is extensive preclinical evidence supporting the testing of HDAC inhibitors in SCCHN. HDAC inhibitors have radio-enhancing properties $[75,76]$, increase the susceptibility of SCC cell lines to cisplatin in vitro $[77,78]$, and inhibit tumor growth in xenograft models of SCCHN [79]. Bruzzese et al. [80] demonstrated that the histone deacetylase inhibitor vorinostat in combination with the EGFR tyrosine kinase inhibitor gefitinib induced synergistic inhibition of proliferation, migration, and invasion as well as induction of apoptosis in SCCHN cells, including cells resistant to gefitinib.

4.4. Aurora $A$ and B. High expression of aurora A or B is associated with a worse outcome in SCCHN [81-86].

Hoellein et al. [87] combined a dual aurora A/aurora B inhibitor with cetuximab in SCCHN cell lines in vitro and observed at least an additive effect. Aurora kinase inhibition was able to overcome resistance to cetuximab [87].

4.5. Mammalian Target of Rapamycin. Preclinical data strongly support the testing of mammalian target of rapamycin (mTOR) in SCCHN [88-90]. Activation of mTOR is observed in the majority of SCCHN [91] and is associated with a poor outcome [92]. Patel et al. [93] found that inhibition of mTOR diminished lymphangiogenesis in the primary tumors and prevented the dissemination of SCCHN cancer cells to the cervical lymph nodes in an orthotopic mouse model [93]. Temsirolimus enhances the growth-inhibiting effects of the combination of bevacizumab, cetuximab, and irradiation in head and neck cancer xenografts [94]. Aissat et al. [95] demonstrated that rapamycin displays antiproliferative effects and induces apoptosis in SCCHN cell lines and that combination of rapamycin with paclitaxel or carboplatin displayed synergistic and additive effects [95]. Temsirolimus appeared to be a more potent radiosensitizer than cisplatin in mice bearing squamous cell carcinoma xenografts [96]. In a pharmacodynamic evaluation of temsirolimus in SCCHN patients, Ekshyyan et al. found a significant inhibition of the mTOR pathways in tumor cells and in peripheral blood mononuclear cells [97]. Everolimus $10 \mathrm{mg} /$ day, days 1-21 can be safely combined with cisplatin $20 \mathrm{mg} / \mathrm{m}^{2}$, days 1,8 , and 15 of a 28-day cycle in patients with solid tumors [98].

4.6. $c$-Src. c-Src is a nonreceptor cytoplasmic tyrosine kinase that regulates signals from cell surface molecules and that plays a key role in modulating multiple cellular functions by activating the signal transducer and activator of transcription
(STAT) family of transcription factors. Although preclinical data provided a rationale for testing $\mathrm{c}-\mathrm{Scr}$ inhibitors in SCCHN, the outcome with single-agent c-Scr inhibitors in patients with R/M SCCHN was disappointing. Brooks et al. [99] treated $15 \mathrm{R} / \mathrm{M}$ SCCHN patients with dasatinib, a potent inhibitor of Src-family kinases EphA2, at a dose $100 \mathrm{mg}$ twice daily. No objective responses were observed and the median PFS was less than 1 month. Saracatinib is also an orally available Src kinase inhibitor which was administered to 9 R/M SCCHN patients at a daily dose of $175 \mathrm{mg}$ [100]. Eight patients had disease progression within the first eight-week cycle, and one patient was removed from the study after 11 days due to rapid clinical decline. The study was closed early due to lack of efficacy according to the early stopping rule [100].

4.7. Phosphatidylinositol-3-Kinase. Rampias et al. [101] detected HRAS mutations in $29 \%$ of 105 SCCHN specimens. Four percent of the specimens harbored PIK3CA mutations. Cell lines bearing HRAS or PIK3CA mutations are resistant to cetuximab. This resistance can be overcome by addition of a PI3K inhibitor.

4.8. Nuclear Factor Kappa B. Nuclear factor kappa B is overexpressed in SCCHN, and NF- $\kappa \mathrm{B}$ expression is associated with a poor prognosis. Bortezomib is a small-molecule proteasome inhibitor which affects multiple signaling pathways including NF- $\kappa \mathrm{B}$. Chung et al. treated $25 \mathrm{R} / \mathrm{M}$ SCCHN patients with bortezomib $1.6 \mathrm{mg} / \mathrm{m}^{2}$ and docetaxel $40 \mathrm{mg} / \mathrm{m}^{2}$ on days 1 and 8 of a 21-day cycle and observed a ORR and DCR of 5 and $52 \%$, respectively.

\section{Combination of Targeted Agents}

Cohen et al. [102] combined erlotinib $150 \mathrm{mg} /$ day and bevacizumab IV every 3 weeks. As no dose-limiting toxicities were observed in the phase I portion of the study which included 10 patients up to the maximum planned dose of $15 \mathrm{mg} / \mathrm{kg}$ of bevacizumab, 46 additional patients were treated at that dose level. Forty-eight percent of the patients had received prior chemotherapy for recurrent/metastatic disease. The combination was well tolerated. Three patients (5\%) experienced serious bleeding events. The observed response rate was $15 \%$ with 4 complete responses allowing rejection of the null hypothesis that the response rate is $\leq 5 \%$ and the percentage of patients not progressing within two months is $\leq 30 \%$. The median OS and PFS were 7.1 and 4.1 months, respectively. Higher ratios of phosphorylated over total VEGF receptor-2 and EGFR in pretreatment biopsies were associated with complete response $(P=0.036$ and $P=$ 0.036 , resp.) and tumor shrinkage $(P=0.007$ and $P=0.008$, resp.) in a subset of 11 subjects with available tissue [102].

The feasibility and efficacy of adding bevacizumab and erlotinib to concurrent CRT in patients with LA SCCHN was evaluated in a phase II trial conducted by the Sarah Cannon oncology research consortium including 60 previously untreated patients [103]. The treatment consisted of induction chemotherapy with 6 weeks of paclitaxel, carboplatin, infusional 5-fluorouracil, and bevacizumab, which was 
followed by radiation therapy, weekly paclitaxel, bevacizumab, and erlotinib. After a median followup of 32 months, the estimated 3-year PFS and OS rates are $71 \%$ and $82 \%$, respectively. Grade 3/4 mucosal toxicity occurred frequently $(88 \%)$ during combined modality. No unexpected toxicity resulted from the addition of bevacizumab and erlotinib.

Integrins promote and regulate endothelial cell proliferation, migration, invasion, and survival in tumors, securing vascularisation and vascular remodeling in tumors. Cilengitide is a selective inhibitor of the $\alpha \mathrm{v} \beta 3 / 5$ integrins. ADVANTAGE [104] is a phase I/II trial evaluating cilengitide in combination with cetuximab, cisplatin and 5-fluorouracil in patients with R/M SCCHN. No DLTs were observed in the phase I part of the study which tested cilengitide (500, 1000 , and $2000 \mathrm{mg}$ ) twice weekly with standard doses of cetuximab, cisplatin and 5-fluorouracil. Cilengitide $2000 \mathrm{mg}$ was considered safe and was selected for the subsequent randomised phase II part assessing PFS [104].

\section{Conclusion}

The road from preclinical evidence to clinical use is long and bumpy, and a large number of targeted agents are still at the start of the race. Some others reached the last stretch but stumbled on one of the last hurdles in phase II, or even phase III trials. Thus far, only the EGFR-directed monoclonal antibody cetuximab has made it to the finish and is currently approved for the treatment of locoregionally advanced and recurrent/metastatic SCCHN, by the regulatory agencies of the United States and Europe.

\section{References}

[1] http://globocan.iarc.fr.

[2] R. I. Haddad and D. M. Shin, "Recent advances in head and neck cancer," The New England Journal of Medicine, vol. 359, no. 11, pp. 1143-1154, 2008.

[3] http://www.cancer.gov/clinicaltrials/search.

[4] J. R. Grandis and D. J. Tweardy, "Elevated levels of transforming growth factor $\alpha$ and epidermal growth factor receptor messenger RNA are early markers of carcinogenesis in head and neck cancer," Cancer Research, vol. 53, no. 15, pp. 35793584, 1993.

[5] K. K. Ang, B. A. Berkey, X. Tu et al., "Impact of epidermal growth factor receptor expression on survival and pattern of relapse in patients with advanced head and neck carcinoma," Cancer Research, vol. 62, no. 24, pp. 7350-7356, 2002.

[6] C. H. Chung, K. Ely, L. McGavran et al., "Increased epidermal growth factor receptor gene copy number is associated with poor prognosis in head and neck squamous cell carcinomas," Journal of Clinical Oncology, vol. 24, no. 25, pp. 4170-4176, 2006.

[7] A. N. Demiral, S. Sarioglu, B. Birlik, M. Sen, and M. Kinay, "Prognostic significance of EGF receptor expression in early glottic cancer," Auris Nasus Larynx, vol. 31, no. 4, pp. 417424, 2004.

[8] http://www.ema.europa.eu/docs/en_GB/document_library/EPAR_-_Product_Information/human/000558/ WC500029119.pdf.

[9] http://www.accessdata.fda.gov/drugsatfda_docs/label/2009/ 125084s168lbl.pdf.
[10] J. Marshall, "Clinical implications of the mechanism of epidermal growth factor receptors inhibitors," Cancer, vol. 107, no. 6, pp. 1207-1218, 2006.

[11] H. Modjtahedi, "Molecular therapy of head and neck cancer," Cancer and Metastasis Reviews, vol. 24, no. 1, pp. 129-146, 2005.

[12] R. Mehra, R. B. Cohen, and B. A. Burtness, "The role of cetuximab for the treatment of squamous cell carcinoma of the head and neck," Clinical Advances in Hematology and Oncology, vol. 6, no. 10, pp. 742-750, 2008.

[13] J. A. Bonner, P. M. Harari, J. Giralt et al., "Radiotherapy plus cetuximab for locoregionally advanced head and neck cancer: 5-year survival data from a phase 3 randomised trial, and relation between cetuximab-induced rash and survival," The Lancet Oncology, vol. 11, no. 1, pp. 21-28, 2010.

[14] J. A. Bonner, P. M. Harari, J. Giralt et al., "Radiotherapy plus cetuximab for squamous-cell carcinoma of the head and neck," The New England Journal of Medicine, vol. 354, no. 6, pp. 567-578, 2006.

[15] J. P. Pignon, J. Bourhis, C. Domenge, and L. Designé, “Chemotherapy added to locoregional treatment for head and neck squamous-cell carcinoma: three meta-analyses of updated individual data. MACH-NC collaborative group. meta-analysis of chemotherapy on head and neck cancer," The Lancet, vol. 355, no. 9208, pp. 949-955, 2000.

[16] J. P. Pignon, A. L. Maître, E. Maillard, and J. Bourhis, "Metaanalysis of chemotherapy in head and neck cancer (MACHNC): an update on 93 randomised trials and 17,346 patients," Radiotherapy \& Oncology, vol. 92, no. 1, pp. 4-14, 2009.

[17] K. K. Ang, Q. Zhang, D. I. Rosenthal et al., "A randomized phase III trial (RTOG 0522) of concurrent accelerated radiation plus cisplatin with or without cetuximab for stage III-IV head and neck squamous cell carcinomas (HNC)," Journal of Clinical Oncology, vol. 29, supplement, abstract no. 5500, 2011.

[18] J. L. Lefebvre, Y. Pointreau, F. Rolland et al., "Sequential chemoradiotherapy (SCRT) for larynx preservation (LP): results of the randomized phase II TREMPLIN study," Journal of Clinical Oncology, vol. 29, supplement, abstract no. 5501, 2011.

[19] T. Y. Seiwert, D. J. Haraf, E. E. Cohen et al., "A randomized phase II trial of cetuximab-based induction chemotherapy followed by concurrent cetuximab, 5-FU, hydroxyurea, and hyperfractionated radiation (CetuxFHX), or cetuximab, cisplatin, and accelerated radiation with concomitant boost (CetuxPX) in patients with locoregionally advanced head and neck cancer (HNC)," Journal of Clinical Oncology, vol. 29, supplement, abstract no. 5519, 2011.

[20] A. Argiris, M. V. Karamouzis, R. Smith et al., "Phase I trial of pemetrexed in combination with cetuximab and concurrent radiotherapy in patients with head and neck cancer," Annals of Oncology, vol. 22, no. 11, pp. 2482-2488, 2011.

[21] H. Wanebo, M. S. Ghebremichael, B. A. Burtness et al., "Phase II induction cetuximab (C225), paclitaxel (P), and carboplatin (C) followed by chemoradiation with C225, P, C, and RT 68-72Gy for stage III/IV head and neck squamous cancer: primary site organ preservation and disease control at 2 years (ECOG, E2303)," Journal of Clinical Oncology, vol. 28, no. 15, supplement, abstract no. 5513, 2010.

[22] W. Jordan, I. Wildfang, H. Welkoborsky et al., “TPF induction-radioimmunochemotherapy for the treatment of advanced head and neck cancer," Journal of Clinical Oncology, vol. 28, no. 15, supplement, abstract no. 5514, 2010. 
[23] R. L. Ferris, D. E. Heron, S. Kim et al., "Induction docetaxel, cisplatin, and cetuximab (TPE) followed by concurrent radiotherapy, cisplatin, and cetuximab and maintenance cetuximab in patients with locoregionally advanced head and neck cancer (HNC): Mature results with HPV analysis," Journal of Clinical Oncology, vol. 28, no. 15, supplement, abstract no. 5515, 2010.

[24] R. Mesia, A. Rueda, R. Vera et al., "Is there a role for adjuvant cetuximab after radiotherapy (RT) plus cetuximab in patients (pts) with locally advanced squamous cell carcinoma of the oropharynx? A phase II randomized trial," Journal of Clinical Oncology, vol. 28, no. 15, supplement, abstract no. 5534, 2010.

[25] J. B. Vermorken, R. Mesia, F. Rivera et al., "Platinum-based chemotherapy plus cetuximab in head and neck cancer," The New England Journal of Medicine, vol. 359, no. 11, pp. 11161127, 2008.

[26] B. Burtness, M. A. Goldwasser, W. Flood, B. Mattar, and A. A. Forastiere, "Phase III randomized trial of cisplatin plus placebo compared with cisplatin plus cetuximab in metastatic/recurrent head and neck cancer: an Eastern cooperative oncology group study," Journal of Clinical Oncology, vol. 23, no. 34, pp. 8646-8654, 2005.

[27] R. Hitt, A. Irigoyen, H. Cortes-Funes, J. J. Grau, J. A. GarciaSaenz, and J. J. Cruz-Hernandez, "Phase II study of the combination of cetuximab and weekly paclitaxel in the firstline treatment of patients with recurrent and/or metastatic squamous cell carcinoma of head and neck," Annals of Oncology, vol. 23, no. 4, pp. 1016-1022, 2012.

[28] J. Guigay, J. Fayette, A. F. Dillies et al., "Cetuximab, docetaxel, and cisplatin (TPEx) as first-line treatment in patients with recurrent or metastatic (R/M) squamous cell carcinoma of the head and neck (SCCHN): first results of phase II trial GORTEC 2008-03," Journal of Clinical Oncology, vol. 29, supplement, abstract no. 5567, 2011.

[29] I. Tinhofer, K. Klinghammer, W. Weichert et al., "Interference of amphiregulin and EGFRvIII expression with outcome of patients with squamous cell carcinoma of the head and neck (SCCHN) receiving cetuximab-docetaxel treatment," Journal of Clinical Oncology, vol. 29, supplement, abstract no. 5508, 2011.

[30] J. Baselga, J. M. Trigo, J. Bourhis et al., "Phase II multicenter study of the antiepidermal growth factor receptor monoclonal antibody cetuximab in combination with platinumbased chemotherapy in patients with platinum-refractory metastatic and/or recurrent squamous cell carcinoma of the head and neck," Journal of Clinical Oncology, vol. 23, no. 24, pp. 5568-5577, 2005.

[31] R. S. Herbst, M. Arquette, D. M. Shin et al., "Phase II multicenter study of the epidermal growth factor receptor antibody cetuximab and cisplatin for recurrent and refractory squamous cell carcinoma of the head and neck," Journal of Clinical Oncology, vol. 23, no. 24, pp. 5578-5587, 2005.

[32] J. B. Vermorken, J. Trigo, R. Hitt et al., "Open-label, uncontrolled, multicenter phase II study to evaluate the efficacy and toxicity of cetuximab as a single agent in patients with recurrent and/or metastatic squamous cell carcinoma of the head and neck who failed to respond to platinum-based therapy," Journal of Clinical Oncology, vol. 25, no. 16, pp. 2171-2177, 2007.

[33] J. B. Vermorken, R. S. Herbst, X. Leon, N. Amellal, and J. Baselga, "Overview of the efficacy of cetuximab in recurrent and/or metastatic squamous cell carcinoma of the head and neck in patients who previously failed platinum-based therapies," Cancer, vol. 112, no. 12, pp. 2710-2719, 2008.

[34] X. León, R. Hitt, M. Constenla et al., "A retrospective analysis of the outcome of patients with recurrent and/or metastatic squamous cell carcinoma of the head and neck refractory to a platinum-based chemotherapy," Clinical Oncology, vol. 17, no. 6, pp. 418-424, 2005.

[35] M. Fury, E. J. Sherman, D. M. Lisa et al., "A randomized phase II study of cetuximab (C) every 2 weeks at either 500 or 750 $\mathrm{mg} / \mathrm{m} 2$ for patients (Pts) with recurrent or metastatic (R/M) head and neck squamous cell cancer (HNSCC)," Journal of Clinical Oncology, vol. 29, supplement, abstract no. 5563, 2011.

[36] J. P. Machiels, S. Subramanian, A. Ruzsa et al., "Zalutumumab plus best supportive care versus best supportive care alone in patients with recurrent or metastatic squamous-cell carcinoma of the head and neck after failure of platinumbased chemotherapy: an open-label, randomised phase 3 trial," The Lancet Oncology, vol. 12, no. 4, pp. 333-343, 2011.

[37] J. B. Vermorken, J. Stöhlmacher, I. Davidenko et al., "Primary efficacy and safety results of SPECTRUM, a phase 3 trial of recurrent and/or metastatic squamous cell carcinoma of the head and neck receiving chemotherapy with or without panitumumab," Annals of Oncology, vol. 21, supplement 8, abstract no. LBA26, 2010.

[38] M. Gupta, V. Madholia, and K. T. Bhowmik, "Results from a pilot study of nimotuzumab with concurrent chemoradiation in patients with locally advanced squamous cell carcinoma of head and neck," Journal of Clinical Oncology, vol. 28, no. 15, supplement, abstract no. 5565, 2010.

[39] M. O. Rodríguez, T. C. Rivero, B. R. del Castillo et al., "Nimotuzumab plus radiotherapy for unresectable squamous-cell carcinoma of the head and neck," Cancer Biology and Therapy, vol. 9, no. 5, pp. 343-349, 2010.

[40] K. G. Babu, L. Viswanath, B. K. Reddy et al., "An open-label, randomized, study of h-R3mAb (nimotuzumab) in patients with advanced (stage III or IVa) squamous cell carcinoma of head and neck (SCCHN): four-year survival results from a phase IIb study," Journal of Clinical Oncology, vol. 28, no. 15, supplement, abstract no. 5530, 2010.

[41] A. Argiris, M. S. Ghebremichael, J. Gilbert, B. A. Burtness, and A. A. Forastiere, "A phase III randomized, placebocontrolled trial of docetaxel (D) with or without gefitinib (G) in recurrent or metastatic $(\mathrm{R} / \mathrm{M})$ squamous cell carcinoma of the head and neck (SCCHN): a trial of the Eastern cooperative oncology group (ECOG)," Journal of Clinical Oncology, vol. 27, no. 15, supplement, abstract no. 6011, 2009.

[42] J. S. Stewart, E. E. Cohen, L. Licitra et al., "Phase III study of gefitinib 250 compared with intravenous methotrexate for recurrent squamous cell carcinoma of the head and neck," Journal of Clinical Oncology, vol. 27, no. 11, pp. 1864-1871, 2009.

[43] E. E. Cohen, F. Rosen, W. M. Stadler et al., "Phase II trial of ZD1839 in recurrent or metastatic squamous cell carcinoma of the head and neck," Journal of Clinical Oncology, vol. 21, no. 10, pp. 1980-1987, 2003.

[44] E. E. Cohen, M. A. Kane, M. A. List et al., "Phase II trial of gefitinib $250 \mathrm{mg}$ daily in patients with recurrent and/or metastatic squamous cell carcinoma of the head and neck," Clinical Cancer Research, vol. 11, no. 23, pp. 8418-8424, 2005.

[45] A. M. Kirby, R. P. A'Hern, C. D’Ambrosio et al., "Gefitinib (ZD1839, Iressa) as palliative treatment in recurrent or 
metastatic head and neck cancer," British Journal of Cancer, vol. 94, no. 5, pp. 631-636, 2006.

[46] D. Soulieres, N. N. Senzer, E. E. Vokes, M. Hidalgo, S. S. Agarvala, and L. L. Siu, "Multicenter phase II study of erlotinib, an oral epidermal growth factor receptor tyrosine kinase inhibitor, in patients with recurrent or metastatic squamous cell cancer of the head and neck," Journal of Clinical Oncology, vol. 22, no. 1, pp. 77-85, 2004.

[47] C. A. Perez, H. Song, L. E. Raez, M. Agulnik, T. A. Grushko, and A. Dekker, "Phase II study of gefitinib adaptive dose escalation to skin toxicity in recurrent and/or metastatic squamous cell carcinoma of the head and neck," Journal of Clinical Oncology, vol. 29, supplement, abstract no. 5517, 2011.

[48] W. N. William Jr., R. S. Weber, J. J. Lee, J. Myers, L. E. Ginsberg, and A. K. El-Naggar, "Randomized trial of a short course of erlotinib 150 to $300 \mathrm{mg}$ daily prior to surgery for squamous cell carcinomas of the head and neck (SCCHN) in current, former, and never smokers: objective responses and clinical outcomes," Journal of Clinical Oncology, vol. 29, supplement, abstract no. 5520, 2011.

[49] D. N. Hayes, L. E. Raez, A. K. Sharma et al., "Multicenter randomized phase II trial of combined radiotherapy and cisplatin with or without erlotinib in patients with locally advanced squamous cell carcinoma of the head and neck (SCCAHN): preliminary toxicity results," Journal of Clinical Oncology, vol. 28, no. 15, supplement, abstract no. 5580, 2010.

[50] V. Gregoire, M. Hamoir, C. Chen et al., "Gefitinib plus cisplatin and radiotherapy in previously untreated head and neck squamous cell carcinoma: a phase II, randomized, doubleblind, placebo-controlled study," Radiotherapy \& Oncology, vol. 100, no. 1, pp. 62-69, 2011.

[51] D. Soulieres, B. Fortin, E. Winquist, D. Charpentier, E. Harnett, and W. Parulekar, "HN5: a phase I/II study of erlotinib as adjuvant therapy in patients treated by chemoradiation therapy (CRT) for locally advanced SCCHN," Journal of Clinical Oncology, vol. 28, no. 15, supplement, abstract no. 5562, 2010.

[52] T. Y. Seiwert, J. Fayette, J. M. Del Campo et al., "Updated results of a randomized, open-label phase II study exploring BIBW 2992 versus cetuximab in patients with platinumrefractory metastatic/reciurrent head and neck cancer (SCCHN)," Annals of Oncology, vol. 21, supplement 8, abstract no. 1010PD, 2010.

[53] K. J. Harrington, A. Berrier, M. Robinson et al., "Phase II study of oral lapatinib, a dual-tyrosine kinase inhibitor, combined with chemoradiotherapy (CRT) in patients (pts) with locally advanced, unresected squamous cell carcinoma of the head and neck (SCCHN)," Journal of Clinical Oncology, vol. 15, supplement, abstract no. 5505, 2010.

[54] J. M. Del Campo, R. Hitt, P. Sebastian et al., "Effects of lapatinib monotherapy: results of a randomised phase II study in therapy-naive patients with locally advanced squamous cell carcinoma of the head and neck," British Journal of Cancer, vol. 105, no. 5, pp. 618-627, 2011.

[55] L. L. Siu, S. J. Hotte, S. A. Laurie et al., "Phase II trial of the irreversible oral pan-human EGF receptor (HER) inhibitor PF-00299804 (PF) as first-line treatment in recurrent and/or metastatic (RM) squamous cell carcinoma of the head and neck (SCCHN)," Journal of Clinical Oncology, vol. 29, supplement, abstract no. 5561, 2011.

[56] P. A. Kyzas, I. W. Cunha, and J. P. Ioannidis, "Prognostic significance of vascular endothelial growth factor immunohistochemical expression in head and neck squamous cell carcinoma: a meta-analysis," Clinical Cancer Research, vol. 11, no. 4, pp. 1434-1440, 2005.

[57] S. Cao, F. A. Durrani, K. Toth, Y. M. Rustum, and M. Seshadri, "Bevacizumab enhances the therapeutic efficacy of irinotecan against human head and neck squamous cell carcinoma xenografts," Oral Oncology, vol. 47, no. 6, pp. 459466, 2011.

[58] K. Fujita, D. Sano, M. Kimura et al., "Anti-tumor effects of bevacizumab in combination with paclitaxel on head and neck squamous cell carcinoma," Oncology Reports, vol. 18, no. 1, pp. 47-51, 2007.

[59] A. Argiris, M. V. Karamouzis, W. E. Gooding et al., "Phase II trial of pemetrexed and bevacizumab in patients with recurrent or metastatic head and neck cancer," Journal of Clinical Oncology, vol. 29, no. 9, pp. 1140-1145, 2011.

[60] T. Y. Seiwert, D. J. Haraf, E. E. Cohen et al., "Phase I study of bevacizumab added to fluorouracil- and hydroxyureabased concomitant chemoradiotherapy for poor-prognosis head and neck cancer," Journal of Clinical Oncology, vol. 26, no. 10, pp. 1732-1741, 2008.

[61] J. K. Salama, D. J. Haraf, K. M. Stenson et al., "A randomized phase II study of 5-fluorouracil, hydroxyurea, and twicedaily radiotherapy compared with bevacizumab plus 5fluorouracil, hydroxyurea, and twice-daily radiotherapy for intermediate-stage and T4N0-1 head and neck cancers," Annals of Oncology, vol. 22, no. 10, pp. 2304-2309, 2011.

[62] P. Harari, D. Khuntia, A. M. Traynor, J. K. Hoang, D. J. Yang, and G. K. Hartig, "Phase I trial of bevacizumab combined with concurrent chemoradiation for squamous cell carcinoma of the head and neck: preliminary outcome results," Journal of Clinical Oncology, vol. 29, supplement, abstract no. 5518, 2011.

[63] C. Elser, L. L. Siu, E. Winquist et al., "Phase II trial of sorafenib in patients with recurrent or metastatic squamous cell carcinoma of the head and neck or nasopharyngeal carcinoma," Journal of Clinical Oncology, vol. 25, no. 24, pp. 3766-3773, 2007.

[64] S. K. Williamson, J. Moon, C. H. Huang et al., "Phase II evaluation of sorafenib in advanced and metastatic squamous cell carcinoma of the head and neck: GORTEC 2006-01," Journal of Clinical Oncology, vol. 28, no. 20, pp. 3330-3335, 2010.

[65] J. P. Machiels, S. Henry, S. Zanetta et al., "Phase II study of sunitinib in recurrent or metastatic squamous cell carcinoma of the head and neck: GORTEC 2006-01," Journal of Clinical Oncology, vol. 28, no. 1, pp. 21-28, 2010.

[66] G. Fountzilas, A. Fragkoulidi, A. Kalogera-Fountzila et al., "A phase II study of sunitinib in patients with recurrent and/or metastatic non-nasopharyngeal head and neck cancer," Cancer Chemotherapy and Pharmacology, vol. 65, no. 4, pp. 649660, 2010.

[67] N. W. Choong, M. Kozloff, D. Taber et al., "Phase II study of sunitinib malate in head and neck squamous cell carcinoma," Investigational New Drugs, vol. 28, no. 5, pp. 677-683, 2010.

[68] A. L. Sabichi, M. S. Kies, B. S. Glisson et al., "A phase II study of sorafenib in combination with carboplatin and paclitaxel in patients with metastatic or recurrent squamous cell cancer of the head and neck (SCCHN)," Journal of Clinical Oncology, vol. 28, no. 15, supplement, abstract no. 5532, 2010.

[69] D. Sano, F. Matsumoto, D. R. Valdecanas et al., "Vandetanib restores head and neck squamous cell carcinoma cells' sensitivity to cisplatin and radiation in vivo and in vitro," Clinical Cancer Research, vol. 17, no. 7, pp. 1815-1827, 2011.

[70] D. Sano, M. Kawakami, K. Fujita et al., "Antitumor effects of ZD6474 on head and neck squamous cell carcinoma," Oncology Reports, vol. 17, no. 2, pp. 289-295, 2007. 
[71] V. M. Papadimitrakopoulou, J. V. Heymach, S. J. Frank et al., "Updated clinical and biomarker results from a phase I study of vandetanib with radiation therapy (RT) with or without cisplatin in locally advanced head and neck squamous cell carcinoma (HNSCC)," Journal of Clinical Oncology, vol. 29, supplement, abstract no. 5510, 2011.

[72] T. Okui, T. Shimo, N. M. Hassan et al., "Antitumor effect of novel HSP90 inhibitor NVP-AUY922 against oral squamous cell carcinoma," Anticancer Research, vol. 31, no. 4, pp. 11971204, 2011.

[73] T. Y. Alhazzazi, P. Kamarajan, E. Verdin, and Y. L. Kapila, "SIRT3 and cancer: tumor promoter or suppressor?" Biochimica et Biophysica Acta, vol. 1816, no. 1, pp. 80-88, 2011.

[74] T. Y. Alhazzazi, P. Kamarajan, N. Joo et al., "Sirtuin-3 (SIRT3), a novel potential therapeutic target for oral cancer," Cancer, vol. 117, no. 8, pp. 1670-1678, 2011.

[75] M. Jung, A. Velena, B. Chen, P. A. Petukhov, A. P. Kozikowski, and A. Dritschilo, "Novel HDAC inhibitors with radiosensitizing properties," Radiation Research, vol. 163, no. 5, pp. 488-493, 2005.

[76] Y. Zhang, M. Jung, A. Dritschilo, and M. Jung, "Enhancement of radiation sensitivity of human squamous carcinoma cells by histone deacetylase inhibitors," Radiation Research, vol. 161, no. 6, pp. 667-674, 2004.

[77] H. Rikiishi, F. Shinohara, T. Sato, Y. Sato, M. Suzuki, and S. Echigo, "Chemosensitization of oral squamous cell carcinoma cells to cisplatin by histone deacetylase inhibitor, suberoylanilide hydroxamic acid," International Journal of Oncology, vol. 30, no. 5, pp. 1181-1188, 2007.

[78] T. Sato, M. Suzuki, Y. Sato, S. Echigo, and H. Rikiishi, "Sequence-dependent interaction between cisplatin and histone deacetylase inhibitors in human oral squamous cell carcinoma cells," International Journal of Oncology, vol. 28, no. 5, pp. 1233-1241, 2006.

[79] R. B. Erlich, Z. Kherrouche, D. Rickwood et al., "Preclinical evaluation of dual PI3K-mTOR inhibitors and histone deacetylase inhibitors in head and neck squamous cell carcinoma," British Journal of Cancer, vol. 106, no. 1, pp. 107$115,2011$.

[80] F. Bruzzese, A. Leone, M. Rocco et al., "HDAC inhibitor vorinostat enhances the antitumor effect of gefitinib in squamous cell carcinoma of head and neck by modulating ErbB receptor expression and reverting EMT," Journal of Cellular Physiology, vol. 226, no. 9, pp. 2378-2390, 2011.

[81] E. García-Fernández, J. I. De Diego, E. Collantes-Bellido et al., "Aurora B kinase expression in laryngeal squamous cell carcinoma and its prognostic implications," Histopathology, vol. 58, no. 3, pp. 368-376, 2011.

[82] Z. Guan, X. R. Wang, X. F. Zhu et al., "Aurora-A, a negative prognostic marker, increases migration and decreases radiosensitivity in cancer cells," Cancer Research, vol. 67, no. 21, pp. 10436-10444, 2007.

[83] G. Pannone, S. A. Hindi, A. Santoro et al., "Aurora B expression as a prognostic indicator and possible therapeutic target in oral squamous cell carcinoma," International journal of immunopathology and pharmacology, vol. 24, no. 1, pp. 79$88,2011$.

[84] G. Qi, I. Ogawa, Y. Kudo et al., "Aurora-B expression and its correlation with cell proliferation and metastasis in oral cancer," Virchows Archiv, vol. 450, no. 3, pp. 297-302, 2007.

[85] R. Reiter, P. Gais, U. Jutting et al., "Aurora kinase A messenger RNA overexpression is correlated with tumor progression and shortened survival in head and neck squamous cell carcinoma," Clinical Cancer Research, vol. 12, no. 17, pp. 5136-5141, 2006.
[86] H. Zhang, X. Chen, Y. Jin, B. Liu, and L. Zhou, "Overexpression of Aurora-A promotes laryngeal cancer progression by enhancing invasive ability and chromosomal instability," European Archives of Oto-Rhino-Laryngology, vol. 269, no. 2, pp. 607-614, 2012.

[87] A. Hoellein, A. Pickhard, F. von Keitz et al., "Aurora kinase inhibition overcomes cetuximab resistance in squamous cell cancer of the head and neck," Oncotarget, vol. 2, no. 8, pp. 599-609, 2011.

[88] F. Schedel, R. Pries, B. Thode et al., "mTOR inhibitors show promising in vitro activity in bladder cancer and head and neck squamous cell carcinoma," Oncology Reports, vol. 25, no. 3, pp. 763-768, 2011.

[89] K. Y. Chang, S. Y. Tsai, C. M. Wu, C. J. Yen, B. F. Chuang, and J. Y. Chang, "Novel phosphoinositide 3-kinase/mTOR dual inhibitor, NVP-BGT226, displays potent growth-inhibitory activity against human head and neck cancer cells in vitro and in vivo," Clinical Cancer Research, vol. 17, no. 22, pp. 7116-7126, 2011.

[90] S. S. Khariwala, J. Kjaergaard, R. Lorenz, F. Van Lente, S. $\mathrm{Shu}$, and M. Strome, "Everolimus (RAD) inhibits in vivo growth of murine squamous cell carcinoma (SCC VII)," Laryngoscope, vol. 116, no. 5, pp. 814-820, 2006.

[91] A. A. Molinolo, S. M. Hewitt, P. Amornphimoltham et al., "Dissecting the Akt/mammalian target of rapamycin signaling network: emerging results from the head and neck cancer tissue array initiative," Clinical Cancer Research, vol. 13, no. 17, pp. 4964-4973, 2007.

[92] E. Massarelli, D. D. Liu, J. J. Lee et al., "Akt activation correlates with adverse outcome in tongue cancer," Cancer, vol. 104, no. 11, pp. 2430-2436, 2005.

[93] V. Patel, C. A. Marsh, R. T. Dorsam et al., "Decreased lymphangiogenesis and lymph node metastasis by mTOR inhibition in head and neck cancer," Cancer Research, vol. 71, no. 22, pp. 7103-7112, 2011.

[94] A. Bozec, M. C. Etienne-Grimaldi, J. L. Fischel et al., "The mTOR-targeting drug temsirolimus enhances the growthinhibiting effects of the cetuximab-bevacizumab-irradiation combination on head and neck cancer xenografts," Oral Oncology, vol. 47, no. 5, pp. 340-344, 2011.

[95] N. Aissat, C. Le Tourneau, A. Ghoul et al., "Antiproliferative effects of rapamycin as a single agent and in combination with carboplatin and paclitaxel in head and neck cancer cell lines," Cancer Chemotherapy and Pharmacology, vol. 62, no. 2, pp. 305-313, 2008.

[96] O. Ekshyyan, Y. Rong, X. Rong et al., "Comparison of radiosensitizing effects of the mammalian target of rapamycin inhibitor CCI-779 to cisplatin in experimental models of head and neck squamous cell carcinoma," Molecular Cancer Therapeutics, vol. 8, no. 8, pp. 2255-2265, 2009.

[97] O. Ekshyyan, G. M. Mills, T. Lian et al., "Pharmacodynamic evaluation of temsirolimus in patients with newly diagnosed advanced-stage head and neck squamous cell carcinoma," Head \& Neck, vol. 32, no. 12, pp. 1619-1628, 2010.

[98] M. G. Fury, E. Sherman, S. Haque et al., "A phase I study of daily everolimus plus low-dose weekly cisplatin for patients with advanced solid tumors," Cancer Chemotherapy and Pharmacology, vol. 69, no. 3, pp. 591-598, 2012.

[99] H. D. Brooks, B. S. Glisson, B. N. Bekele et al., "Phase 2 study of dasatinib in the treatment of head and neck squamous cell carcinoma," Cancer, vol. 117, no. 10, pp. 2112-2119, 2011.

[100] M. G. Fury, S. Baxi, R. Shen et al., "Phase II study of saracatinib (AZD0530) for patients with recurrent or metastatic head and neck squamous cell carcinoma (HNSCC)," Anticancer Research, vol. 31, no. 1, pp. 249-253, 2011. 
[101] T. Rampias, A. Giagini, K. Florou et al., "H-RAS and PIK3CA mutations and response to cetuximab in head and neck squamous cell carcinoma (HNSCC)," Journal of Clinical Oncology, vol. 29, supplement, abstract no. 5513, 2011.

[102] E. E. Cohen, D. W. Davis, T. G. Karrison et al., "Erlotinib and bevacizumab in patients with recurrent or metastatic squamous-cell carcinoma of the head and neck: a phase I/II study," The Lancet Oncology, vol. 10, no. 3, pp. 247-257, 2009.

[103] J. D. Hainsworth, D. R. Spigel, F. A. Greco et al., "Combined modality treatment with chemotherapy, radiation therapy, bevacizumab, and erlotinib in patients with locally advanced squamous carcinoma of the head and neck: a phase II trial of the Sarah Cannon oncology research consortium," The Cancer Journal, vol. 17, no. 5, pp. 267-272, 2011.

[104] J. B. Vermorken, J. Guigay, R. Mesia et al., "Phase I/II trial of cilengitide with cetuximab, cisplatin and 5-fluorouracil in recurrent and/or metastatic squamous cell cancer of the head and neck: findings of the phase I part," British Journal of Cancer, vol. 104, no. 11, pp. 1691-1696, 2011. 


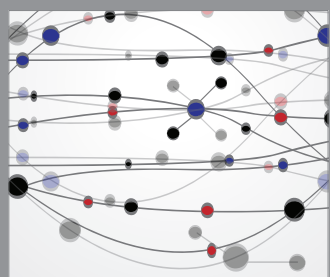

The Scientific World Journal
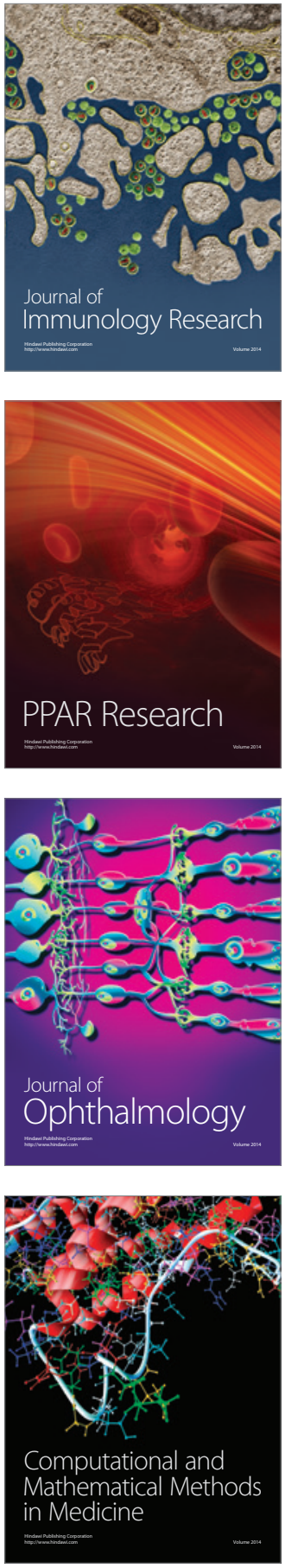

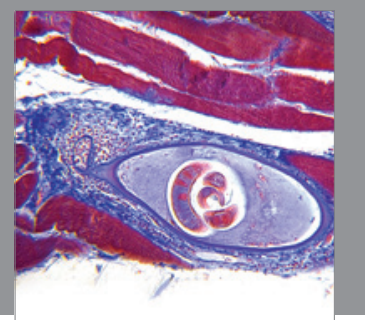

Gastroenterology

Research and Practice
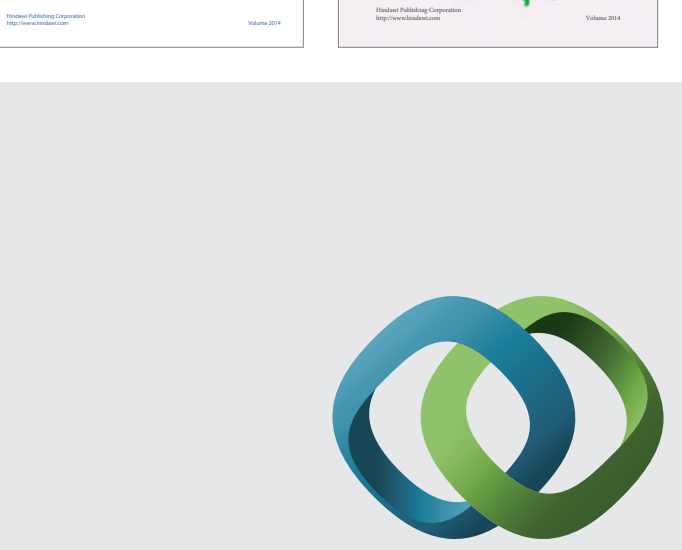

\section{Hindawi}

Submit your manuscripts at

http://www.hindawi.com
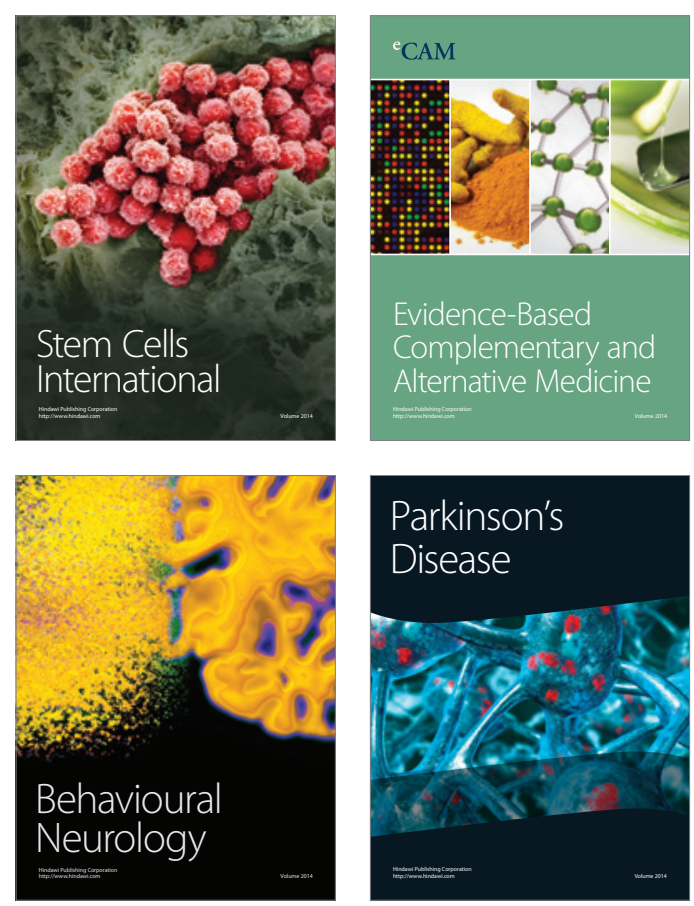

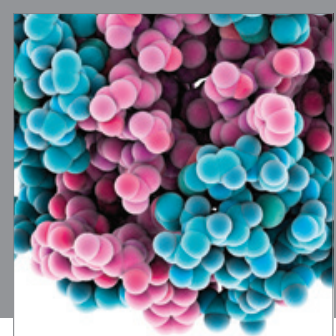

Journal of
Diabetes Research

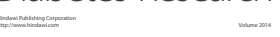

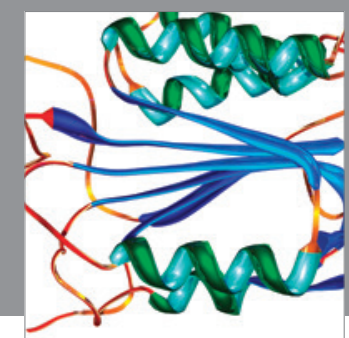

Disease Markers
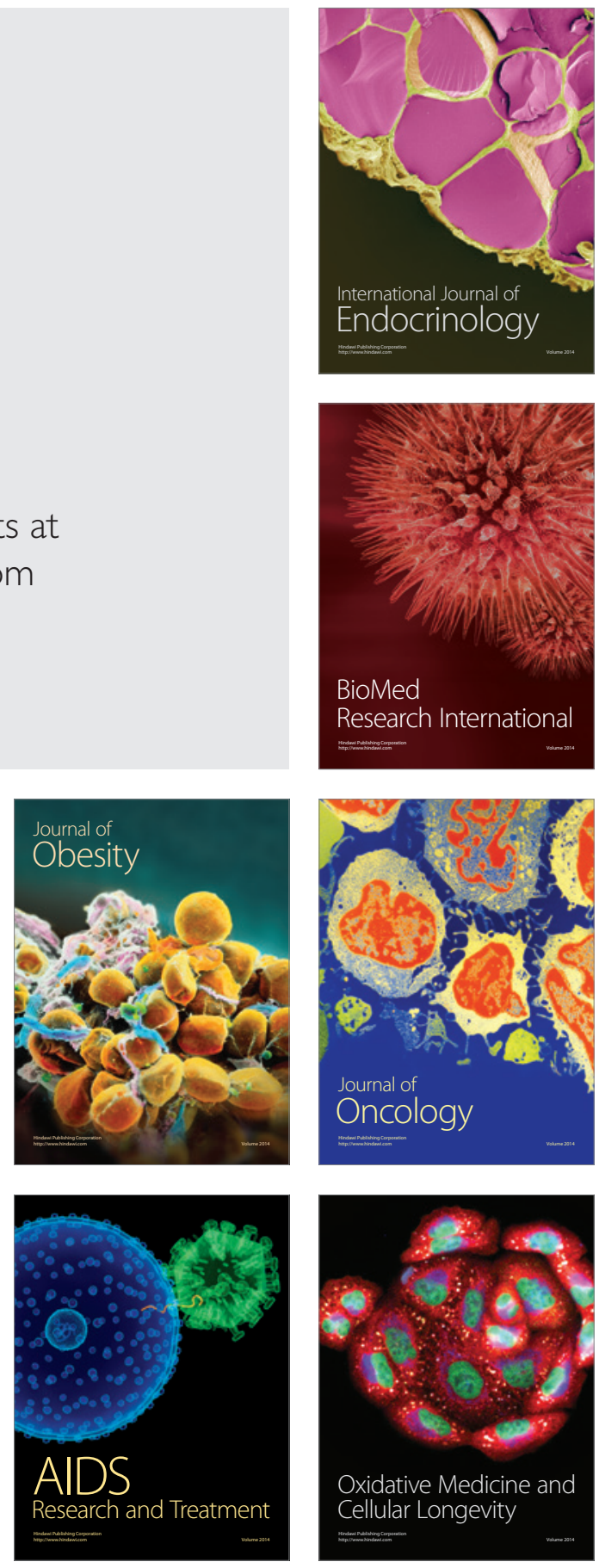